\title{
Effect of neutron and ion irradiation on the metal matrix and oxide corrosion
}

\section{layer on $\mathrm{Zr}-1.0 \mathrm{Nb}$ cladding alloys}

Jing $\mathrm{Hu}^{1,2^{*}}$, Alistair Garner ${ }^{3}$, Philipp Frankel ${ }^{3}$, Meimei $\mathrm{Li}^{2}$, Mark Kirk ${ }^{2}$, Sergio Lozano-Perez ${ }^{1}$, Michael Preuss ${ }^{3}$, Chris Grovenor ${ }^{1}$

1 Department of Materials, University of Oxford, Oxford OX1 3PH, UK;

2 Applied Materials Division, Argonne National Laboratory, Lemont, IL 60439, USA;

3 Materials Performance Centre, School of Materials, University of Manchester, Manchester, UK

*Correspondence author: hujing0321@gmail.com

\section{Abstract}

A detailed study has been carried out on recrystallised $\mathrm{Zr}-1.0 \mathrm{Nb}$ alloys corroded and irradiated under different conditions, including ex-autoclave and ex-reactor samples. After 540 days in reactor and damage around $5 \mathrm{dpa}$, the neutron irradiated sample shows no serious evidence for radiation enhanced corrosion and is still in pre-transition stage. The good corrosion resistance of the neutron irradiated $\mathrm{Zr}-1.0 \mathrm{Nb}$ can be related to the higher volume fraction of tetragonal phase and fewer interconnected nano porosity/ cracks in the oxide. This indicates less tetragonal to monoclinic transition, leads to more protective oxide in the neutron irradiated sample, containing little evidence for short circuit paths for the penetration of oxygen or water towards the metaloxide interface. These observations on a sample with a slow overall oxidation rate are consistent with the hypothesis that interconnected porosity can lead to early transitions and rapid oxidation. Tetragonal oxide can be either stabilised by irradiation, or stabilised by local release of impurity species from SPPs such as dissolution of Fe from $\mathrm{Zr}-\mathrm{Nb}-\mathrm{Fe}$ precipitates or radiation introduced precipitates (RIPs) which is likely to be small $\beta$-Nb clusters. The oxide consists of well-aligned columnar-equiaxed microstructure in the autoclave sample while a more complex oxide grain 
structure was observed in the neutron-irradiated sample. As oxide continues to grow, there are more $\langle a>$ and $\langle\mathrm{c}>$ loops, dissolved Fe and RIPs in the metal matrix, however, the corrosion rate is low enough for the tetragonal oxide to stabilise and suboxide $+\operatorname{Zr}$ (Osat) phases exist for protectiveness, so there is no enhanced corrosion after radiation. In situ ion irradiation in the TEM revealed no visible defect clusters or voids in the oxide, suggesting that radiation damage to the metal matrix rather than oxide may have a stronger effect on corrosion mechanisms after neutron irradiation, however, cascade damages are not visible in this case. Neutron irradiation also seems to have little effect on promoting fast oxidation or dissolution of $\beta$-Nb precipitates into the surrounding oxide or metal during irradiation. These results are discussed in the light of the current mechanisms for corrosion of nuclear fuel cladding alloys.

\section{Introduction}

$\mathrm{Zr}$ alloys have been chosen as the cladding to isolate the nuclear fuel pellets from the coolant water in pressurised water reactors (PWRs), and in this harsh environment, these alloys experience high temperature aqueous corrosion resulting in hydrogen pickup (HPU). $\mathrm{Zr}$ oxides formed under autoclave conditions without irradiation have been studied extensively [1-4], and the corrosion and HPU rates related to the initial alloy chemistry and microstructure as well as the characteristics of the oxide films. Most studies report a sudden increase in corrosion rate, called "transition", after 100-300 days, also controlled by the alloy chemistry and microstructure[5,6], and the time to onset of this first period of accelerated corrosion has an important influence on oxide thickness and HPU after much longer service times. Zr-Nb alloys have been shown to exhibit better corrosion and HPU resistance than Zr-Sn alloys out of reactor[7], specifically showing a longer time to transition. 
The accelerating effect of neutron irradiation on the corrosion rate of $\mathrm{Zr}$ alloys has been studied for many years[2,8], and while other $\mathrm{Zr}$ alloys show irradiation-accelerated corrosion[9], some $\mathrm{Zr}$ $\mathrm{Nb}$ alloys can corrode more slowly under irradiation than under autoclave conditions[10]. The reason for this dramatic difference is not fully understood, but it is very important for enabling the high burnup required to maximise economic value from the fuel and to minimise the volume of high level waste that needs to be stored and eventually disposed of.

Two mechanisms that need to be understood in order to predict the corrosion performance of $\mathrm{Zr}$ alloys in service are: (1) how radiation affects the microstructure of the oxide layers, especially the porosity and existence of interfacial suboxide layers, and (2) how irradiation damage redistributes the trace elements that can influence the rate of corrosion by changing the electrical properties of the oxide[11].

Previous work has shown that before transition only limited concentrations of nanoporosity can be detected in the fine grained oxide scale and that a protective layer of suboxide forms at the metaloxide interface[12]. This suboxide has a stoichiometry close to $\mathrm{ZrO}$ and a hexagonal crystal structure with P-62m symmetry and lattice parameters $\mathrm{a}=5.31 \AA$ and $\mathrm{c}=3.20 \AA$, as predicted by $\mathrm{ab}$ initio modelling[4,13]. At transition, the nanopores in the oxide become interconnected, the $\mathrm{ZrO}$ suboxide may be lost and the abrupt acceleration corrosion rate implies that the inner part of the oxide is no longer electrochemically protective[14]. However, there is a lack of corresponding evidence on the role played by porosity and suboxide layers in neutron irradiated samples, especially in the oxide film, in part due to the difficulty in obtaining these samples and then applying to active materials the advanced electron microscopy techniques required to observe the nanostructure features that control corrosion resistance. 
In zirconium alloys the most common defects produced during irradiation include the formation of arrays of parallel dislocation lines or dislocation loops of $\langle a\rangle,\langle\mathrm{c}\rangle$ or $\langle\mathrm{c}+\mathrm{a}\rangle$ character[15,16], and these are observed under both neutron[7,17-20] and ion irradiation[21,22]. At the same time irradiation stimulates the redistribution of trace and alloying elements such as iron, niobium and chromium from SPPs into the corroding metal matrix[23-25], as well as generating point defects that increase the diffusion rates of these elements once they are displaced from the SPPs. For Zr$1.0 \mathrm{Nb}$ alloys, Shishov et al. suggested that under irradiation to 20-30 dpa the $\mathrm{Nb}$ content of the pre-existing $40-50 \mathrm{~nm} \beta-\mathrm{Nb}$ precipitates changed from $80-90$ at $\%$ (unirradiated) to $50-60$ at $\%$ (irradiated), at the same time as the $\mathrm{Nb}$ concentration in the metal matrix decreased from $\sim 0.4$ at $\%$ to below 0.2 at $\%[26]$. The excess $\mathrm{Nb}$ is accommodated in new, fine $(5-10 \mathrm{~nm})$ radiation-induced precipitates (RIPs) which is considered to be $\beta$-Nb clusters. A similar analysis of the E635 (Zr$1 \% \mathrm{Nb}-0.35 \% \mathrm{Fe}-1.2 \% \mathrm{Sn}$ ) alloy containing predominantly $\mathrm{Zr}-\mathrm{Nb}-\mathrm{Fe}$ second phase particles (SPPs) showed that they transform to $\beta-\mathrm{Nb}$ after irradiation, with the $\mathrm{Nb}$ content increasing from 35 at $\%$ to 50 at $\%$ while $\mathrm{Fe}$ decreases from 20 at $\%$ to $5-10$ at\%[27]. These observations imply that after irradiation the $\mathrm{Nb}$ content in the matrix tends to decrease, but that Fe can be displaced into the metal matrix where it can decorate dislocation loops after both neutron[28] and proton irradiation[7].

There is much less reported work on the effect of radiation damage on the oxide scales formed during corrosion in service. Neutron irradiation is predicted to create point defects and enhance diffusivity in the oxide $[8,19,20,29]$ that could lead to accelerated corrosion kinetics. Since the $\mathrm{Zr}$ oxide already has very a complicated nanoscale structure[30], it is difficult to observe and characterise any additional defects resulting from neutron irradiation. In situ ion irradiation under 
TEM on oxidised sample provides an alternative way to study whether irradiation creates any defects in the oxide and metal matrix in real time during ion irradiation.

In this work, we compare observations made using a range of advanced electron microscopy techniques on a set of recrystallised $\mathrm{Zr}-1.0 \mathrm{Nb}$ alloys after autoclave and in-reactor corrosion. The aim is to improve our understanding of any changes in microstructure and microchemistry in both oxide and metal matrix, which may play a role in controlling the corrosion rate under irradiation. We have also used in situ ion irradiation of oxidised samples in the transmission electron microscope (TEM) to study real time defect formation in both the oxide and metal matrix.

\section{Materials and Methods}

A set of $\mathrm{Zr}-1.0 \mathrm{Nb}$ samples has been selected to represent exposure to three different conditions: autoclave oxidation, in service reactor conditions, including neutron and gamma irradiation, and in situ ion irradiation in the TEM. The composition of the alloys was measured by EDF Energy using inductively coupled plasma atomic emission spectrometry (ICP-AES) as $\mathrm{Zr}-0.9 \mathrm{Nb}-0.01 \mathrm{Sn}-$ $0.08 \mathrm{Fe}$ (wt \%), as seen in Table 1. All samples were in the recrystallised state with the final heat treatment above the eutectoid temperature to form SPPs of $\beta-\mathrm{Nb}$ and the $\mathrm{Zr}-\mathrm{Nb}-\mathrm{Fe}$ phase.

Table 1: Composition in wt $\%$ of zirconium alloy used in this study.

\begin{tabular}{|c|c|c|c|c|c|c|}
\hline Sample ID & $\mathbf{Z r}(\mathbf{w t} \%)$ & $\mathbf{N b}(\mathbf{w t} \%)$ & $\mathbf{F e}(\mathbf{w t} \%)$ & $\mathbf{S n}(\mathbf{w t} \%)$ & $\mathbf{C r}(\mathbf{w t} \%)$ & $\mathbf{O}(\mathbf{w t} \%)$ \\
\hline $\mathrm{Zr}-1.0 \mathrm{Nb}$ & Balance & 0.91 & 0.08 & 0.01 & $<0.01$ & $\sim 1$ \\
\hline
\end{tabular}

Table 2: Samples conditions for the series of $\mathrm{Zr}-1.0 \mathrm{Nb}$ samples selected for study.

\begin{tabular}{|c|c|c|c|c|c|}
\hline Materials & $\begin{array}{c}\text { Sample } \\
\text { ID }\end{array}$ & $\begin{array}{c}\text { Corrosion } \\
\text { duration } \\
\text { (days) }\end{array}$ & $\begin{array}{c}\text { Corrosion } \\
\text { Kinetics } \\
\text { State }\end{array}$ & $\begin{array}{c}\text { Corrosio } \\
\text { n weight } \\
\text { gain }\end{array}$ & $\begin{array}{c}\text { Irradiation } \\
\text { condition }\end{array}$ \\
\hline
\end{tabular}




\begin{tabular}{|c|c|c|c|c|c|c|}
\hline & & $\begin{array}{l}\text { Light } \\
\text { water }\end{array}$ & $\begin{array}{l}\text { Heavy } \\
\text { water }\end{array}$ & & $\left(\mathrm{mg} / \mathrm{dm}^{2}\right)$ & \\
\hline \multirow{4}{*}{$\begin{array}{l}\text { Autoclave } \\
\text { oxidised } \\
\text { (A) }\end{array}$} & A-120 & 120 & 0 & \multirow[t]{2}{*}{ Pre-transition } & 9.0 & NA \\
\hline & A -225 & 180 & 45 & & 29.94 & NA \\
\hline & A -360 & 360 & 0 & Transition & 38.01 & NA \\
\hline & A -585 & 540 & 45 & $\begin{array}{c}\text { Post- } \\
\text { transition }\end{array}$ & 78.67 & NA \\
\hline $\begin{array}{c}\text { Neutron } \\
\text { irradiated } \\
(\mathbf{N})\end{array}$ & $\mathrm{N}-540$ & 540 & 0 & Pre-transition & 30.16 & $\begin{array}{c}\text { neutron, } \\
\mathrm{E}>1 \mathrm{MeV}, \sim 5 \mathrm{dpa}\end{array}$ \\
\hline $\begin{array}{c}\text { Ion } \\
\text { irradiated } \\
\text { (I) }\end{array}$ & $\mathrm{I}-360$ & 360 & 0 & Transition & 38.01 & $\begin{array}{c}\text { Kr ion, } \\
\mathrm{E}=1 \mathrm{MeV}, \sim 5 \mathrm{dpa}\end{array}$ \\
\hline
\end{tabular}

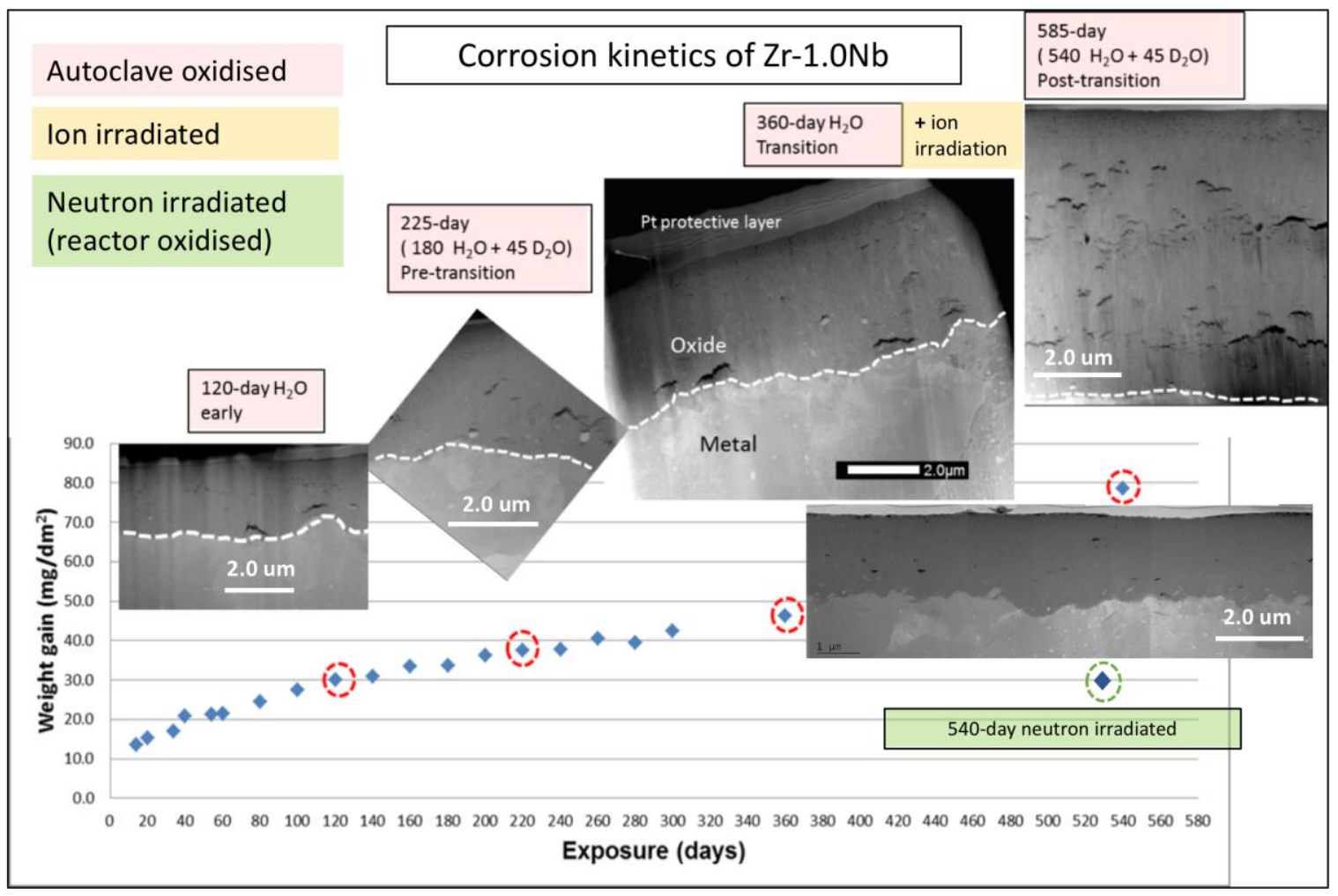

Figure 1: Weight gain as a function of time and typical low magnification HAADF images for the series of $\mathrm{Zr}-1.0 \mathrm{Nb}$ samples selected for study. The 4 materials chosen from the samples corroded in the autoclave are circled. The 360-day autoclave material was subsequently also studied by in- 
situ ion irradiation. The in-reactor temperature of the neutron-irradiated sample was lower (305 $\left.315^{\circ} \mathrm{C}\right)$ than that of the autoclave samples $\left(360^{\circ} \mathrm{C}\right)$.

The autoclave samples in tube geometry were exposed to simulated PWR water conditions at $360^{\circ} \mathrm{C}$ by EDF. We have chosen samples from a larger study at different corrosion stages for which detailed analysis has been reported elsewhere[6,31]. The neutron irradiated sample was a sheet surveillance coupon exposed for one cycle (540 days) in the Vogtle reactor at $\sim 310^{\circ} \mathrm{C}$. The estimated fast neutron fluence accumulated was $4.35 \times 1025 \mathrm{n} / \mathrm{m} 2, \mathrm{E}>1 \mathrm{MeV}$, which is around 5 dpa and approximately a third of the fluence that a typical fuel cladding sees by end of life. This treatment does not fully correspond to in-reactor conditions for cladding tubes since the coupon was not subjected to any stress during irradiation, but provides a direct comparison with similarly unstressed autoclave oxidised samples. The weight gain data and low magnification STEMHAADF images from these samples are shown in Figure 1 and Table 2.

TEM lamellae were prepared by the in-situ lift-out method in a FEI FIB200. For the neutronirradiated samples, first stage FIB in-situ lift out was carried out in the active laboratories in Studsvik, Sweden. There was no prior oxide polishing before lift-out, i.e. the whole oxide thickness was retained. Two TEM lamellae were prepared with sizes $\sim 10 \mu \mathrm{m} \times 10 \mu \mathrm{m} \times 2 \mu \mathrm{m}$ in order to minimize activity and facilitate transportation. All the TEM lamella were further thinned at the University of Oxford with a Zeiss Nvision 40 dual beam FIB down to a thickness 100 nm with $30 \mathrm{kV} \mathrm{Ga}$ ions with a final low energy polish with $2-5 \mathrm{kV} \mathrm{Ga}+$ ions to a final thickness of $\sim 50 \mathrm{~nm}$. (S)TEM analysis of autoclave-oxidised and neutron-irradiated samples was performed on a JEOL 2100 microscope operated at $200 \mathrm{kV}$. Fresnel imaging at $1000 \mathrm{~nm}$ over and under-focus was used to reveal nano-porosity in the oxide films[32]. EDX mapping was acquired using an Oxford Instrument $80 \mathrm{~mm}$ thin window EDX detector in the TEM [3], the data shown in this paper has 
used its original counts without enhancing the contrast. Scanning precession electron diffraction (SPED) was performed in an FEI Tecnai F30 Field Emission Gun Transmission Electron Microscope (FEG-TEM) operated at $300 \mathrm{keV}$, with precession angle of $0.8^{\circ}$ and $5 \mathrm{~nm}$ step size. Data acquisition and analysis was carried out using a NanoMEGAS ASTAR automated crystal orientation mapping system.

Samples for in situ ion-irradiation in the TEM were chosen from the 360-day autoclave oxidised material. In situ ion irradiation at around $310^{\circ} \mathrm{C}$ was conducted at the Intermediate Voltage Electron Microscope-Tandem user facility[33] at the Argonne National Laboratory. $1 \mathrm{MeV} \mathrm{Kr2+}$ ions were used to irradiate the thin TEM foil with a dose rate of $6^{*} 10^{11} \mathrm{ions} / \mathrm{cm}^{2} / \mathrm{sec}$, and the final dpa calculated using SRIM2013 software and the Kinchin-Pease method[34,35] to be 5 dpa in the metal. Under these conditions, all the ions penetrate through the thin foil. (S)TEM analysis of the ion-irradiated sample was carried out on a Hitachi-9000 microscope operating at $300 \mathrm{kV}$. Realtime recording of defect nucleation and evolution was captured on the high-speed CCD camera and screen capture software.

\section{Results}

\subsection{Comparing autoclave oxidised and neutron irradiated samples: overview of oxide}

\section{structure}

Autoclave samples were chosen at different stages of oxidation to describe the general evolution of microstructure (Figure 1). According to an earlier autoclave study [6], the $\mathrm{Zr}-1.0 \mathrm{Nb}$ sample has very good corrosion resistance, and showed no sign of transition even after 360 days. The 120 -day sample represents an early stage of oxidation with an average oxide thickness of $2.2 \mu \mathrm{m}$. The 225- 
day sample represents a stage before the first kinetic transition[6] when the oxide thickness has grown to around $2.6 \mu \mathrm{m}$. The 360 -day sample is taken at approximately the first transition in oxidation kinetics, where the oxide thickness has grown to around $3.2 \mu \mathrm{m}$ and the metal-oxide interface remains relatively flat with characteristic large cracks are formed parallel to the metal/oxide interface. The 585-day sample is well past the second transition, with a total oxide thickness of around $6.1 \mu \mathrm{m}$ and an additional layer of new oxide grown below the second layer of cracks.

The neutron-irradiated sample had a similar period of reactor exposure, 540 days, but the STEM HAADF overview image in Figure 1 shows a relatively thin oxide layer, suggesting that no kinetic transition has occurred. The metal-oxide interface is slightly uneven and the oxide thickness ranges from 1.7 to $2.3 \mu \mathrm{m}$, with an average thickness of $1.9 \mu \mathrm{m}$. Crack formation has been associated with kinetic transitions in the corrosion rate[36], and the two distinct layers of cracks in the 585-day autoclave sample in Figure 1 follow this pattern. However, the neutron irradiated TEM samples show very few large cracks parallel to the metal-oxide interface, Figure 2 (a), compared to either the 540 day autoclave sample or the 120 day autoclave sample with similar oxide thickness (Figure 1). The influence of the lower in-reactor temperature will be discussed below and is related to the oxide growth rate and the relative tetragonal monoclinic phase fractions within the oxide.

In one of the two TEM samples studied from the neutron-irradiated material, a large vertical crack running from the oxide surface was observed, Figure 2 (c) and (d). Figure 2 (c) was acquired prior to thinning of the bulk sample during TEM specimen preparation in the FIB-SEM to show that this crack was most likely present in the bulk material and was not caused by sample preparation. This type of crack is rarely observed in TEM foils prepared from autoclave-corroded samples $[19,37,38]$ and so cannot be attributed solely to the FIB sample preparation process, but we have 
occasionally seen similar vertical cracks in bulk autoclave samples[39]. Figure 2 (a) shows a low magnification overview of a region of oxide from the neutron-irradiated material without evident vertical cracking, but at higher magnification in Figure 2 (b) also shows parallel micro cracks (dark features in the HAADF image) in the layer of equiaxed grains at the top surface of the oxide, just underneath the Pt protective layer. In the autoclave samples examined in this study, no similar parallel microcracks have been observed near the oxide top surface. This kind of perpendicular crack provides an obvious pathway for water penetration towards the metal-oxide interface, but this particular example does not penetrate wholly through the oxide and there is no sign at the metal-oxide interface of an enhanced oxidation rate at this location.

Another feature observed only in the neutron-irradiated samples is the isolated metallic regions penetrating into the oxide like those identified by the dashed circles in Figure 2 (a). This suggests that the variation in local oxidation kinetics at the metal-oxide interface is greater here than observed in the autoclave samples where the metal oxide interfaces are relatively smooth. These metallic inclusions are not associated with underlying metal grain boundaries, nor with any other obvious microstructural feature in the metal, and will be further discussed below. 


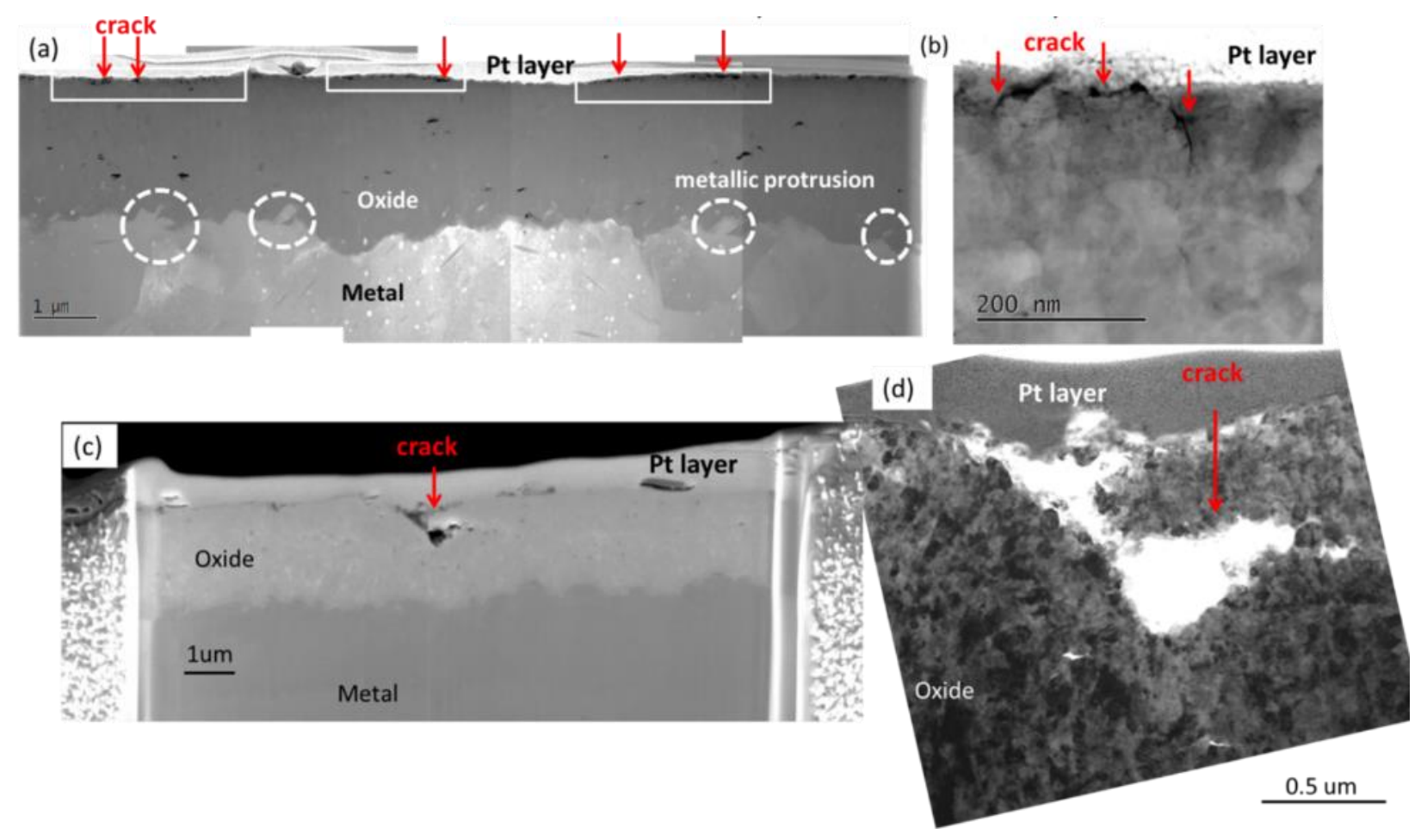

Figure 2: Images from two TEM lamellae from the neutron-irradiated $\mathrm{Zr}-1.0 \mathrm{Nb}$ alloy. (a) low magnification STEM-HAADF image of the first sample, and (b) a higher resolution image of top surface micro cracking. (c) FIB-SEM image of a large crack during preparation of the second TEM sample, and (d) a higher resolution TEM image of the same region.

\subsection{Oxide microstructure}

There are distinctive differences between the oxides grown in the autoclave (120 days, $2.2 \mu \mathrm{m}$ oxide) and in-reactor (540 days, $1.9 \mu \mathrm{m}$ oxide), as can be seen in the bright field TEM images in Figure 3 and the SPED reliability maps in Figure 4. These samples were chosen for comparison because they have a similar oxide thickness and the images in Figure 3 were both taken around 1 $\mu \mathrm{m}$ away from the metal-oxide interface. The oxide formed in the autoclave, Figure 3 (a), has large, elongated columnar grains oriented parallel to the oxide growth direction as previously described[4]. These columnar grains are around $50 \mathrm{~nm}$ in width and 350-450 $\mathrm{nm}$ in length, and 
there is some porosity near the oxide grain boundaries[40] as shown in Figure 5 (a). This is a microstructure characteristic of a slower stage of the oxidation cycle[3]. However, the oxide formed under neutron irradiation, Figure 3 (b), shows a more complex grain structure, with shorter and less organised columnar grains. The general oxide microstructure in Figure 4 (b) is also significantly less regular than found in autoclave samples, i.e. it does not show the well-defined layers of equiaxed-columnar-equiaxed oxide grains often reported[4] and seen in the oxide on the autoclave sample in Figure 4(a).

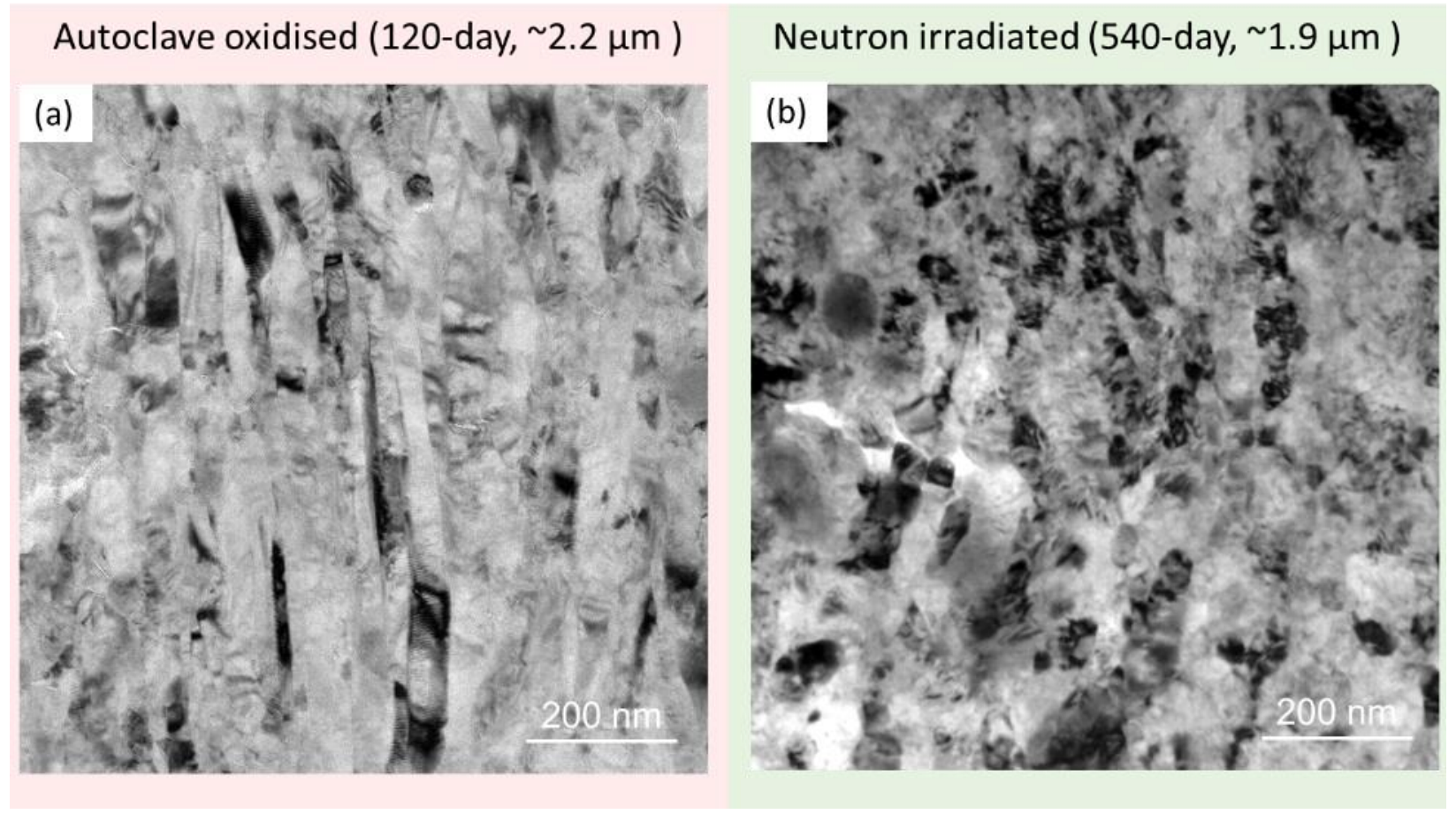

Figure 3: Typical TEM BF images of oxide microstructure in the $\mathrm{Zr}-1.0 \mathrm{Nb}$ samples: (a) autoclave oxidised (b) neutron irradiated sample. Both taken around $1 \mu \mathrm{m}$ away from the metal-oxide interface.

SPED mapping in the TEM was used to map the locations of different phases in these samples. The results on the irradiated sample in Figure 4 (b-1) are similar to the TEM images in Figure 3, showing a more complex oxide grain morphology, with shorter and less organised columnar grains 
compared to the autoclave-oxidised sample in Figure 4 (a-1). We can also see a gradual change in grain size throughout the oxide in the neutron-irradiated sample. In the top $500 \mathrm{~nm}$ of oxide, the average grain size is $60 \mathrm{~nm}$ in width and $130 \mathrm{~nm}$ in length, increasing towards the metal-oxide interface to $70 \mathrm{~nm}-100 \mathrm{~nm}$ in width and an average length of $380 \mathrm{~nm}$.

The SPED phase maps in Figure 4 show that most of the columnar oxide grains are identified as having the monoclinic-ZrO2 (m-ZrO2) structure. However, the irradiated sample in Figure 4 (b-2) contained more tetragonal-ZrO2 (t-ZrO2) grains (coloured red, reliably indexed tetragonal phase fraction: $1.7 \%$ ) around $40-50 \mathrm{~nm}$ in size and found throughout the oxide thickness, when compared with the autoclave sample in Figure 4 (a-2) (reliably indexed tetragonal phase fraction: $0.8 \%$ ). At the metal-oxide interface, there are also larger, columnar tetragonal grains, 50-70 $\mathrm{nm}$ in width and 200-300 $\mathrm{nm}$ long in the neutron irradiated samples. At the metal-oxide interface in both samples the phase maps identify $\mathrm{ZrO}$ suboxide grains with the characteristic Widmanstatten morphology[41]. However in the autoclave samples the $\mathrm{ZrO}$ layer is continuous along the metaloxide interface, as previously observed[4], but the irradiated sample has a much thinner discontinuous suboxide, $50-70 \mathrm{~nm}$, at some locations along the metal-oxide interface there is no detectable suboxide layer at all. These suboxide grains also have a less well-defined saw-tooth shape, but its "barrier" nature is likely to still remain. 

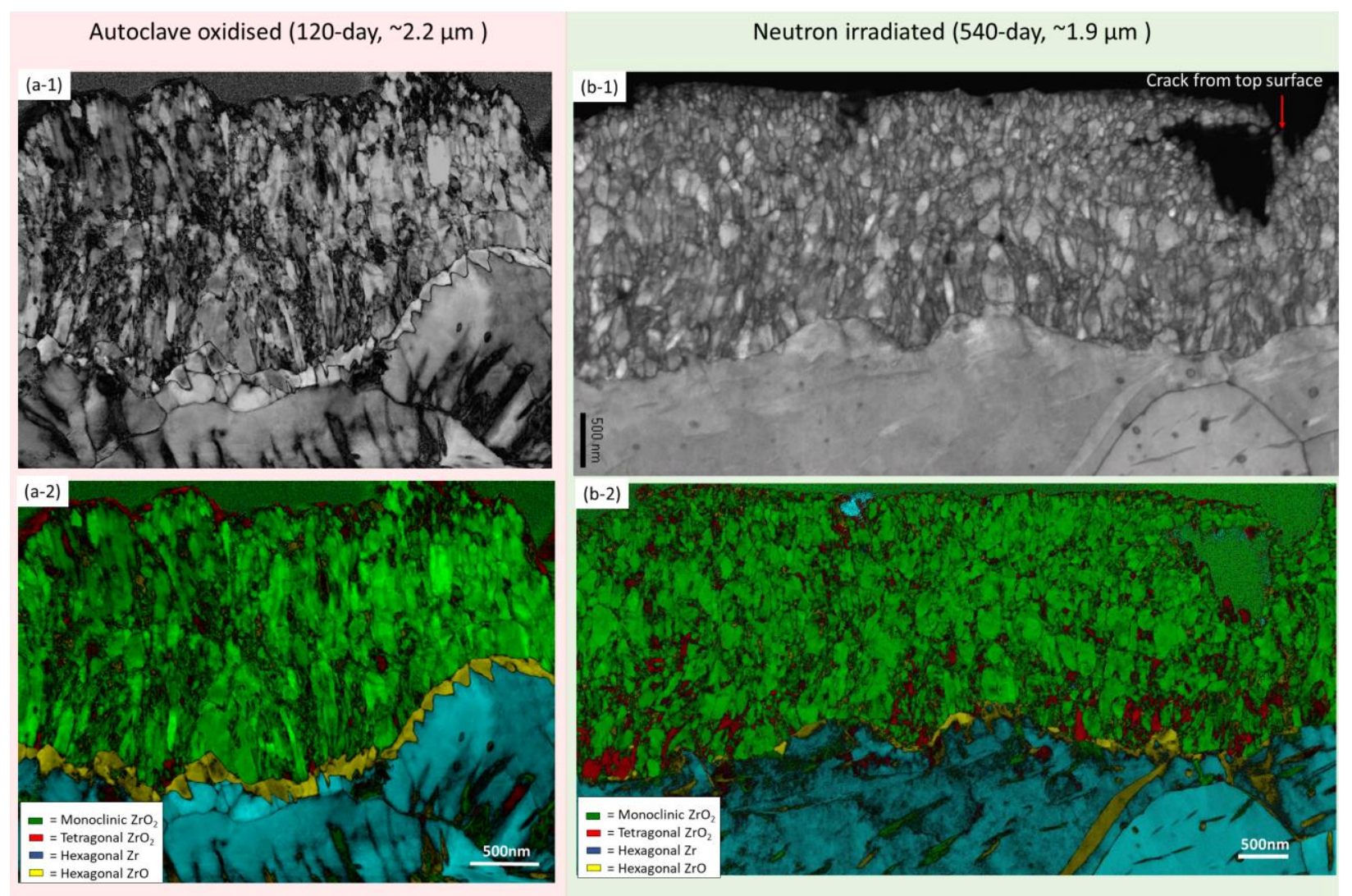

Figure 4: SPED index reliability and phase maps of the TEM lamella from (a) autoclave oxidised and (b) neutron irradiated sample.

The degree of porosity in the neutron-irradiated sample was also significantly lower than in the autoclave sample of similar oxide thickness (Figure 5), measured from the linear density of nanoporosity defined as the total length of nano-pores and nano-pipes along the corrosion direction per unit sample volume. Figure 5(a) shows typical examples of the porosity identified by Fresnel imaging in the autoclave 120 day sample; (a-1) taken $\sim 1 \mu \mathrm{m}$ away from the metal-oxide interface where there are both individual pores and interconnected porosity at the columnar grain boundaries and a total linear density of $\sim 1.7 * 10^{-5} \mathrm{~nm} / \mathrm{nm}^{3}$, and (a-2) taken closer to the metal-oxide interface where isolated and interconnected spherical pores can be seen as well as the small flaky voids also reported by Yilmazbian et al[36], and here the linear density is $\sim 0.6 * 10^{-5} \mathrm{~nm} / \mathrm{nm}^{3}$. However in 
similar images from the neutron irradiated sample in Figure $5(b-1)$ and (b-2), taken at comparative locations in the oxide, it is very difficult to detect any porosity at all, although there is one small crack in (b-2), giving an overall linear density of $\sim 0.2 * 10^{-5} \mathrm{~nm} / \mathrm{nm}^{3}$. When added to the dense oxide microstructure with few obvious cracks shown in Figures 3 and 4, the oxide layer on the neutron-irradiated sample contains little evidence for short circuit paths for the penetration of oxygen or water towards the metal-oxide interface. These observations on a sample with a slow overall oxidation rate (Figure 1) are consistent with the hypothesis that interconnected porosity can lead to early transitions and rapid oxidation[12], and a slow oxidation rate is only seen in oxides without extensive porosity. 

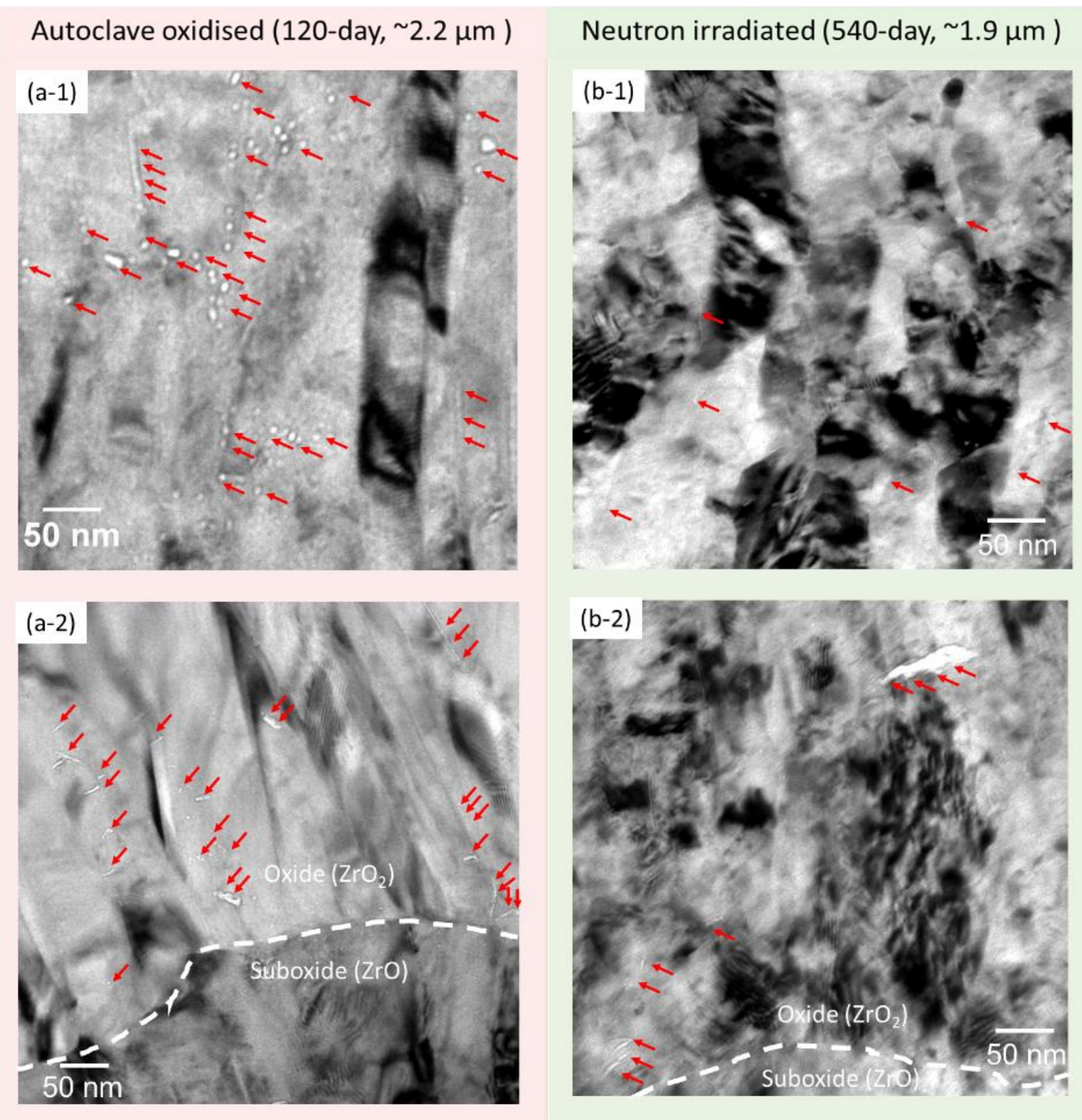

Figure 5: Under-focused TEM images $(\Delta \mathrm{f} \sim 1000 \mathrm{~nm})$ from recrystallised $\mathrm{Zr}-1.0 \mathrm{Nb}$ samples. From the 120 day autoclave sample (a-1) is taken $1 \mu \mathrm{m}$ from the metal-oxide interface and (a-2) near the metal-oxide interface. For the reactor oxidised sample (b-1) is taken $1 \mu \mathrm{m}$ from the metal-oxide interface and (b-2) near the metal-oxide interface. 


\subsection{Second phase particles (SPPs)}

As shown in Figure 6, it is possible by EDX mapping to identify with confidence the location of all the SPPs in these TEM samples due to their different chemical compositions. Two types of SPPs were observed, $\beta-\mathrm{Nb}$ and $\mathrm{Zr}-\mathrm{Nb}-\mathrm{Fe}$ precipitates[42]. The $\mathrm{Nb}$ maps show that $\beta$-Nb SPPs have a roughly uniform distribution in both autoclave and in-reactor materials. These SPPs are $20 \mathrm{~nm}$ to $60 \mathrm{~nm}$ in diameter and roughly spherical in the metallic matrix. They oxidise rapidly when incorporated into the growing oxide layer and become amorphous as previously reported[43,44], and at the same time they expand in the direction of oxidation and become elliptical in shape as oxygen atoms are incorporated (Figure 7). The $\mathrm{Zr}-\mathrm{Nb}-\mathrm{Fe}$ particles in the autoclave sample are easily identified in the Fe maps, and are generally larger (100 - $170 \mathrm{~nm}$ in diameter), have a lower number density and can also sometimes contain Cr. By contrast, in the neutron irradiated samples almost no $\mathrm{Zr}-\mathrm{Nb}$-Fe precipitates can be seen in the $\mathrm{Fe}$ map, and no $\mathrm{Cr}$ was found in any of the particles. The apparent Fe-rich layer at the top surface of the oxide may be a result of CRUD deposition of dissolved $\mathrm{Fe}$ from the reactor water or be formed from Fe released from the irradiated $\mathrm{Zr}-\mathrm{Nb}-\mathrm{Fe}$ SPPs. 

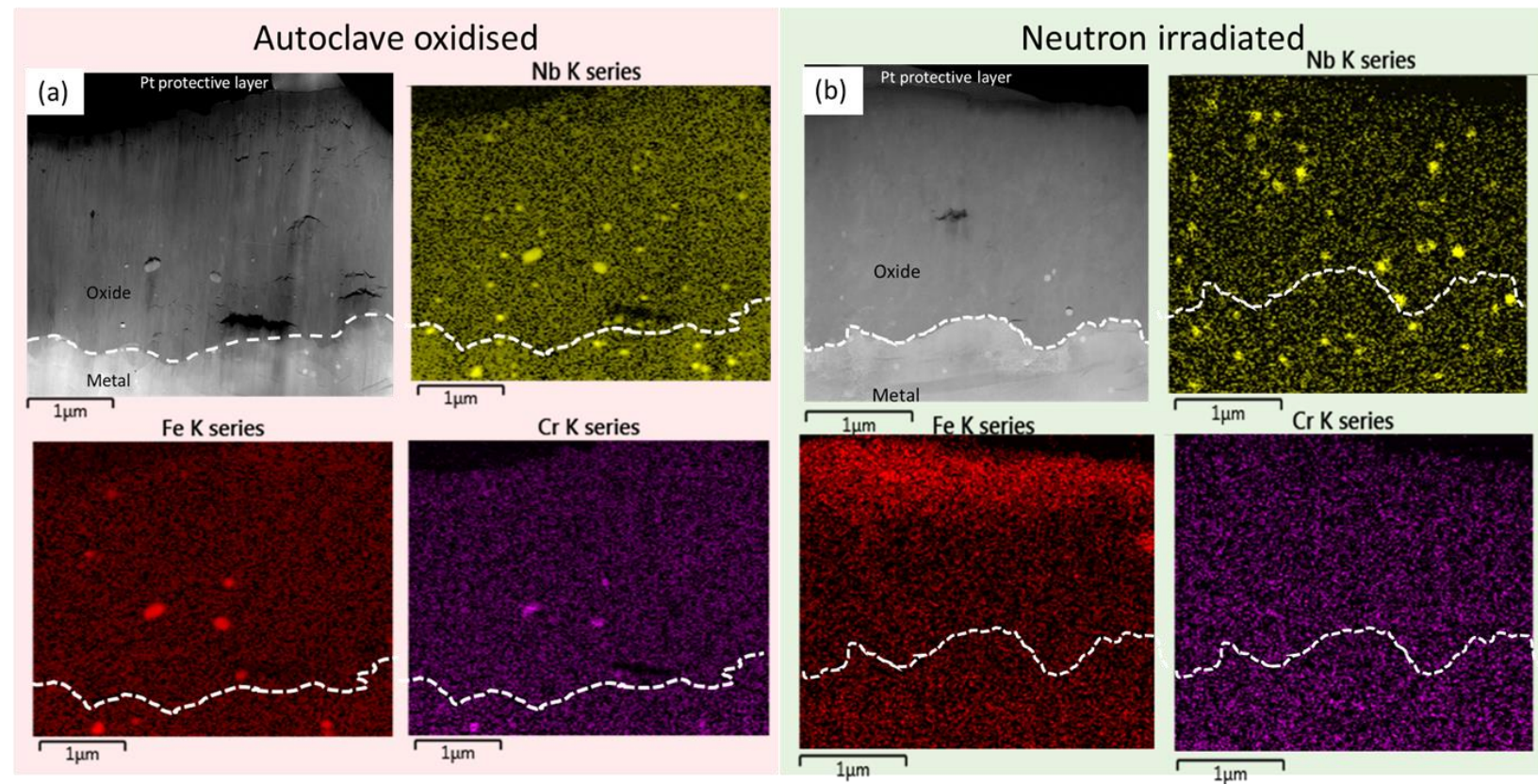

Figure 6: EDX maps of $\mathrm{Nb}, \mathrm{Fe}$ and $\mathrm{Cr}$ in the precipitates in the $\mathrm{Zr}-1.0 \mathrm{Nbsamples:} \mathrm{(a)} 360$ day autoclave sample. (b) in-reactor sample under neutron irradiation for 540 days.

In bright field TEM images, like those shown in Figure 3, SPPs can be hard to detect, but highangle annular dark field (HAADF) imaging is able to differentiate between metallic and oxidised SPPs by the change in average atomic mass (z-contrast), as seen in Figure 7 . When an SPP is oxidised, the overall atomic mass is lower than that of the surrounding $\mathrm{ZrO} 2$ and so the oxidised SPPs appear dark, like those circled in red, while the metallic (un-oxidised) SPPs appear bright (circled in yellow). The higher magnification STEM HAADF image in Figure 7 (b) shows an area near the top surface of the oxide where four oxidised SPPs are circled in red. Partially oxidised SPPs were found around $700 \mathrm{~nm}$ above the metal-oxide interface, and above this region the SPPs were all fully oxidised. Similar observations were made in both autoclave oxidised and neutronirradiated samples. It is clear both from the chemical mapping in Figure 5 and these HAADF images that at this stage of in-reactor exposure that the SPPs have not dissolved into the 
surrounding oxide during irradiation as suggested in previous reports $[45,46]$, but it is possible that some redistribution of $\mathrm{Nb}$ and $\mathrm{Fe}$ has occurred into the nearby oxide.

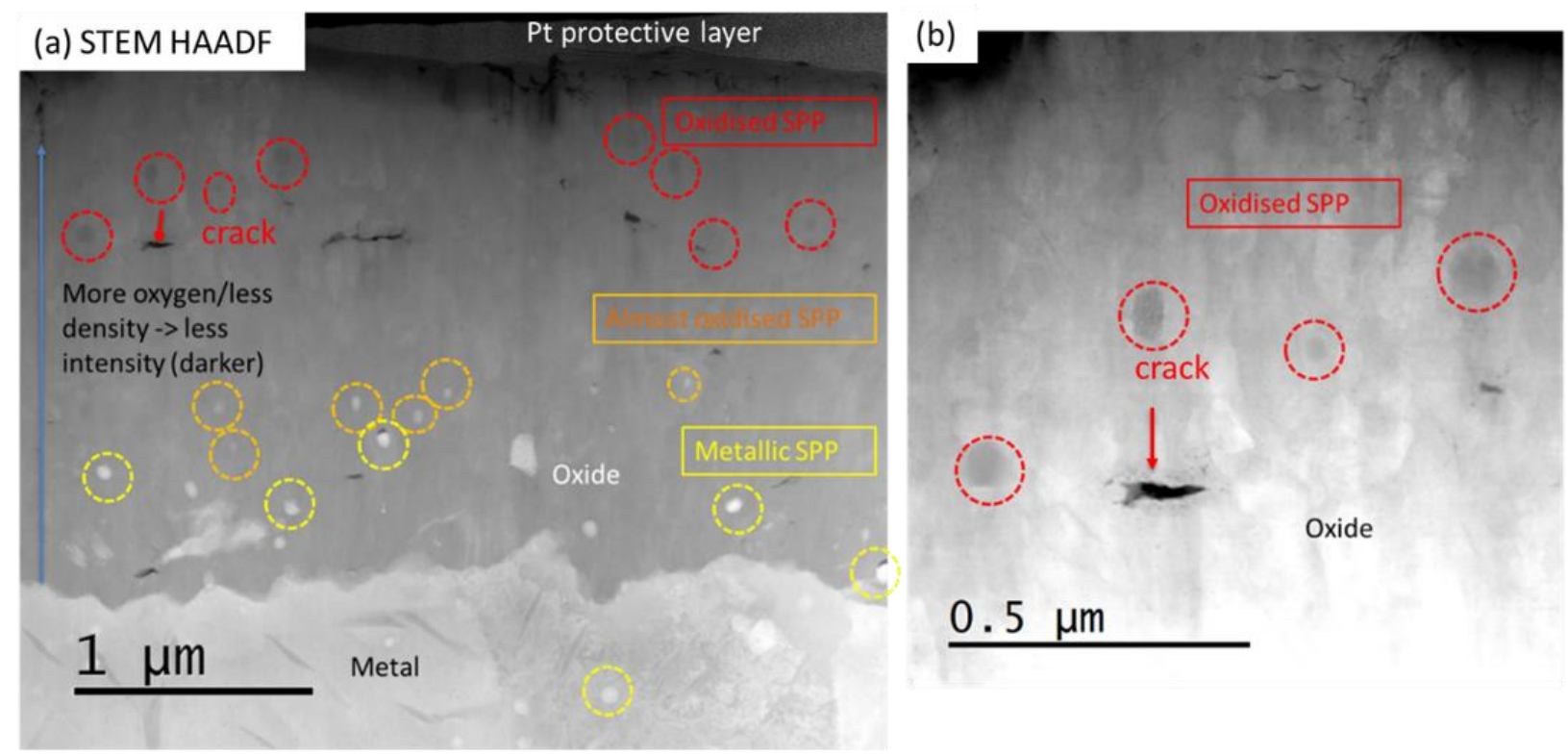

Figure 7: STEM HAADF images from the neutron irradiated $\mathrm{Zr}-1.0 \mathrm{Nb}$ sample showing z-contrast of different oxidation stage of SPPs. (a) a lower magnification image demonstrating the change in contrast as the SPPs become oxidised towards the top of the oxide, and (b) a high magnification image of oxidised SPPs near the upper surface of the oxide.

Figure 8 shows higher magnification EDX mapping of SPPs in the metal substrate of the same neutron irradiated sample. Spherical $\beta$-Nb SPPs are homogenously distributed in the metal, and any Fe that may once have originally been segregated to their surfaces seems to have been lost during irradiation. Before irradiation, there are other types of SPPs such as the $\mathrm{Zr}-\mathrm{Nb}-\mathrm{Fe}$ which sometimes contain Cr. Figure 8 (b) shows a $95 \mathrm{~nm}$ Zr-Nb-Fe particle where the middle 20-25 nm remains enriched in $\mathrm{Cr}$, although $\mathrm{Fe}$ has already been depleted from the whole particle. Previous observations on irradiated alloys have shown similar rapid depletion of Fe from Zr-Nb-Fe SPPs. For instance, work on the E635 (Zr-1\%Nb-0.35\%Fe-1.2\%Sn) alloy shows the Zr-Nb-Fe SPPs 
transformed to $\beta-\mathrm{Nb}$ after irradiation, with the $\mathrm{Nb}$ content increasing from 35 at $\%$ to 50 at $\%$ while Fe decreases from 20 at $\%$ to 5-10 at\%[27]. Similar observations were reported on low tin ZIRLO ${ }^{\circledR}$ after neutron and proton irradiation, where not only is Fe depleted from the Zr-Nb-Fe SPP but the Fe initially decorating $\beta$-Nb particle surfaces is also dissolved into the matrix[47]. After irradiation the displaced Fe can decorate nearby dislocation loops after both neutron[28] and proton irradiation[7].
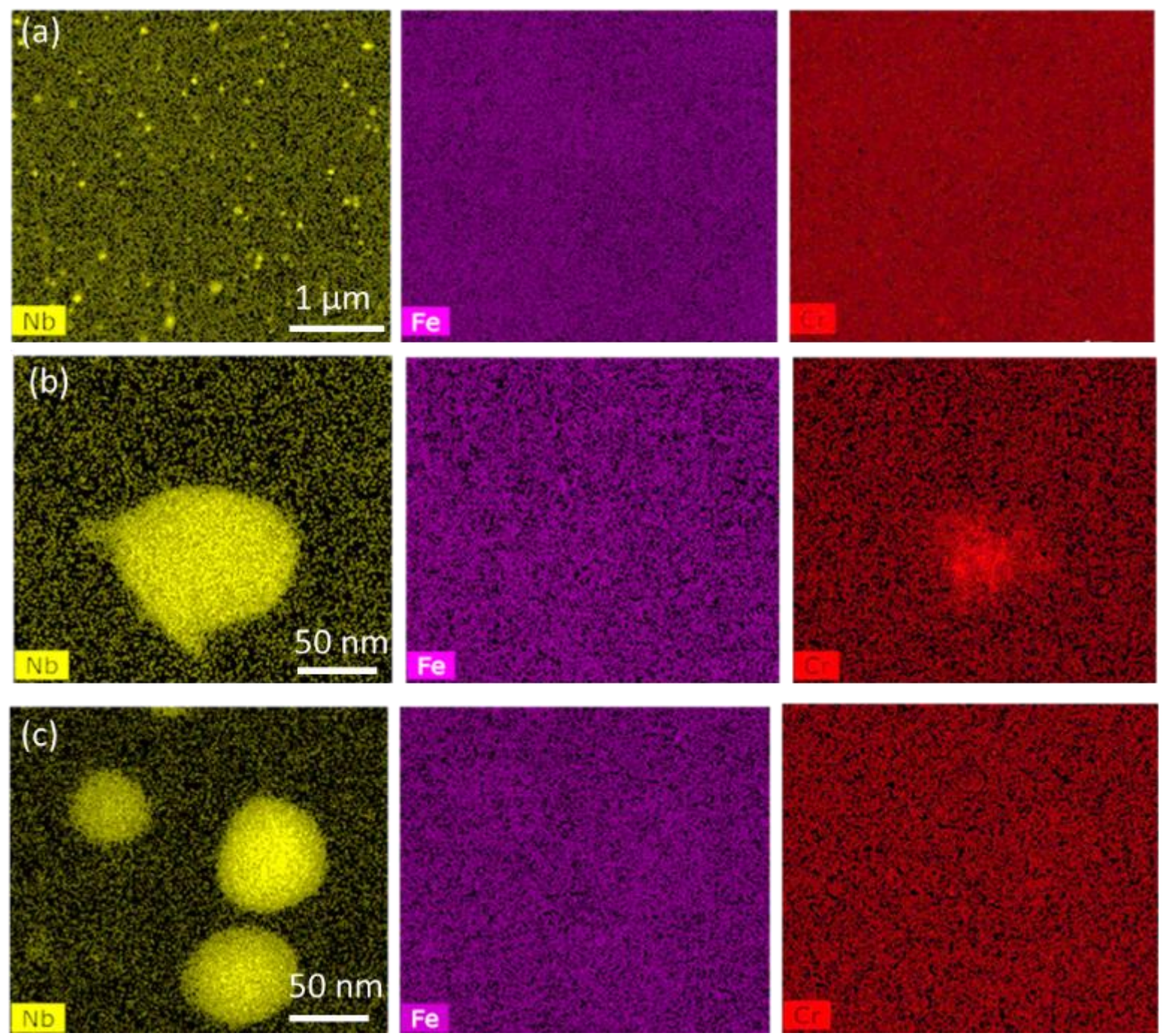

Figure 8: High resolution EDX mapping of SPPs in the metal substrate of the neutron irradiated 
sample: (a) overview (b) Zr-Nb-Fe phase SPP showing Cr remaining in the core of the particle (c) $\beta-\mathrm{Nb}$ particles

\subsection{Metal matrix}

We have carried out a careful study of radiation-induced defects in the metallic matrix of both the neutron- and ion-irradiated specimens. With the metal grains in the neutron irradiated sample orientated with the g vector parallel to [0002], we can easily detect <c>-loops around 40nm in diameter in the bright field TEM images, Figure 9 (c), compared with clean metal matrix before irradiation, Figure 9(a). Features like the radiation-introduced precipitates (RIPs) previously reported in similar alloys have also been observed in the neutron irradiated sample[7,17-20], as circled in Figure 9(d). These have an average size of 5-10 nm, and lie in the same orientation as the $<\mathrm{c}>$-loops. One may argue they can be produced from FIB sample making process, however, previously, similar RIPs are shown using electropolished neutron irradiated samples [17-20].

In-situ ion irradiation provides a convenient way to observe defect generation by radiation damage in real time, although the damage rates will be many orders of magnitude higher than experienced by the in-reactor materials. In-situ observation of the metal microstructure in the autoclaveoxidised sample under irradiation with $1 \mathrm{MeV} \mathrm{Kr}$ ions at $310^{\circ} \mathrm{C}$ (selected to be in the range of LWR operating temperatures) showed the metal grains are very susceptible to damage by ion irradiation. <a>-loops can be detected using $2 \mathrm{~g}$ condition almost from the beginning of the irradiation experiment, even at $0.05 \mathrm{dpa}$, Figure 10 (b), and the density of these loops increases up to $1 \mathrm{dpa}$ when they become hard to separate. The <a>loops also grow with increasing dpa, from an average diameter of $3.2 \mathrm{~nm}$ at $0.05 \mathrm{dpa}$ to $7.4 \mathrm{~nm}$ at $0.5 \mathrm{dpa}$. <c>-loops are not detected until around $3 \mathrm{dpa}$ using $2 \mathrm{~g}$ condition, and continue to grow larger and more numerous during irradiation, Figure 9 (c). Comparing the results at 5 dpa in Figure 9 (b) with the neutron irradiated sample with 
the same total damage in Figure 9 (c), both the density and size of the <c> loops is smaller in the neutron irradiated sample, and radiation-introduced precipitates are not observed in the ion irradiated sample even at $10 \mathrm{dpa}$.
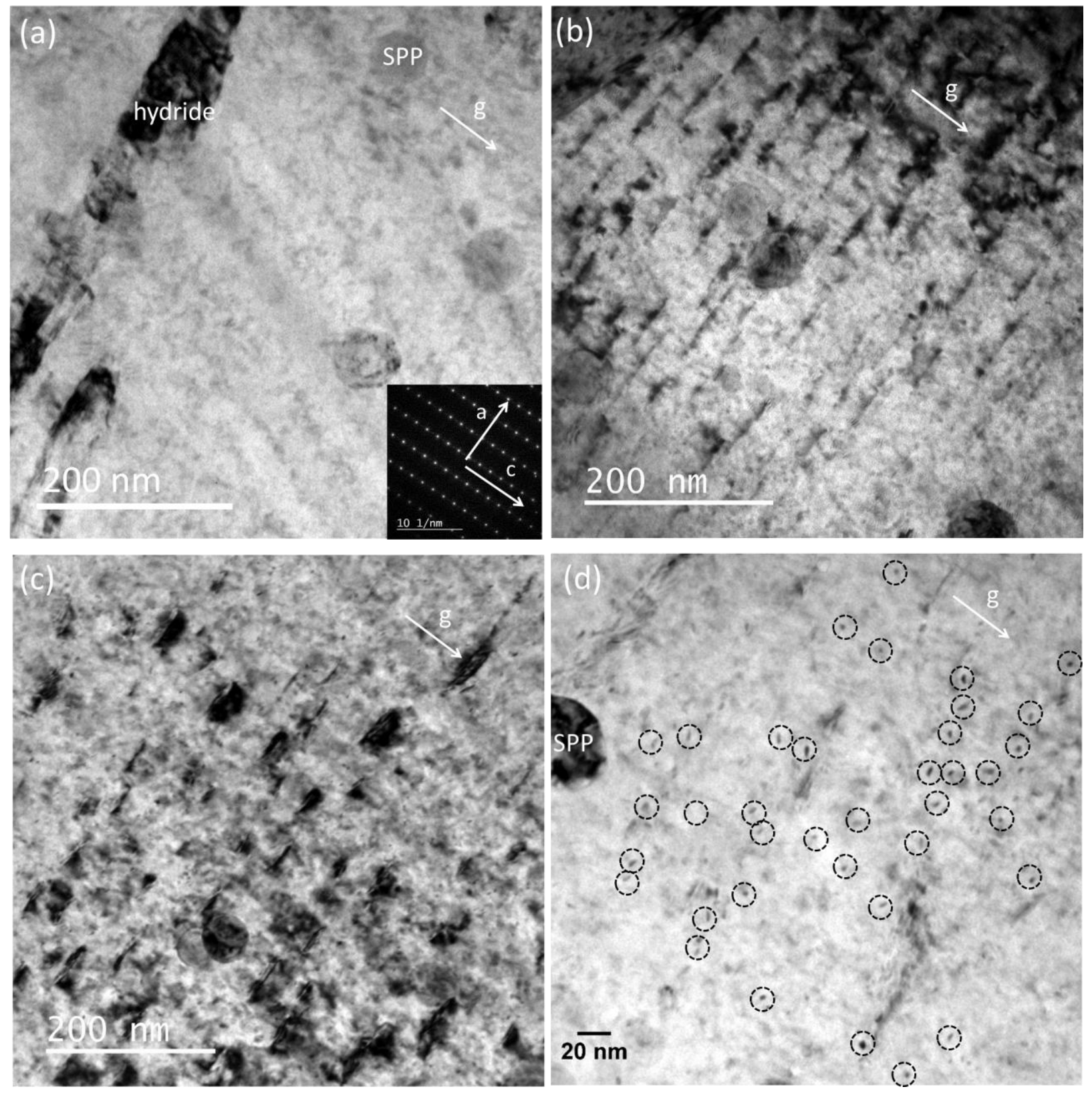

Figure 9: Comparison of metal matrix in (a) autoclave oxidised (b) after ion irradiation to 5 dpa (c) after neutron irradiation to $5 \mathrm{dpa}$, (d) radiation introduced precipitates in the neutron irradiated sample. $g=[0002]$ 
By comparison, in the oxide there is no sign of irradiation defects and no obvious changes in the columnar grain structure, Figure 10 (a). The micro-cracks in the oxide also did not grow during either heating or irradiation. We also noted at this irradiation temperature that the $\mathrm{ZrO}$ suboxide and oxygen saturated $\mathrm{Zr}$ layers at the metal-oxide interface seem stable under ion irradiation. Videos taken during the irradiation process can be found in "Supplementary information", and confirm the lack of amorphisation in these oxide layers during irradiation. This agrees with previous findings showing good irradiation resistance in nanocrystalline materials due to the very high sink density for radiation-induced defects[48,49].
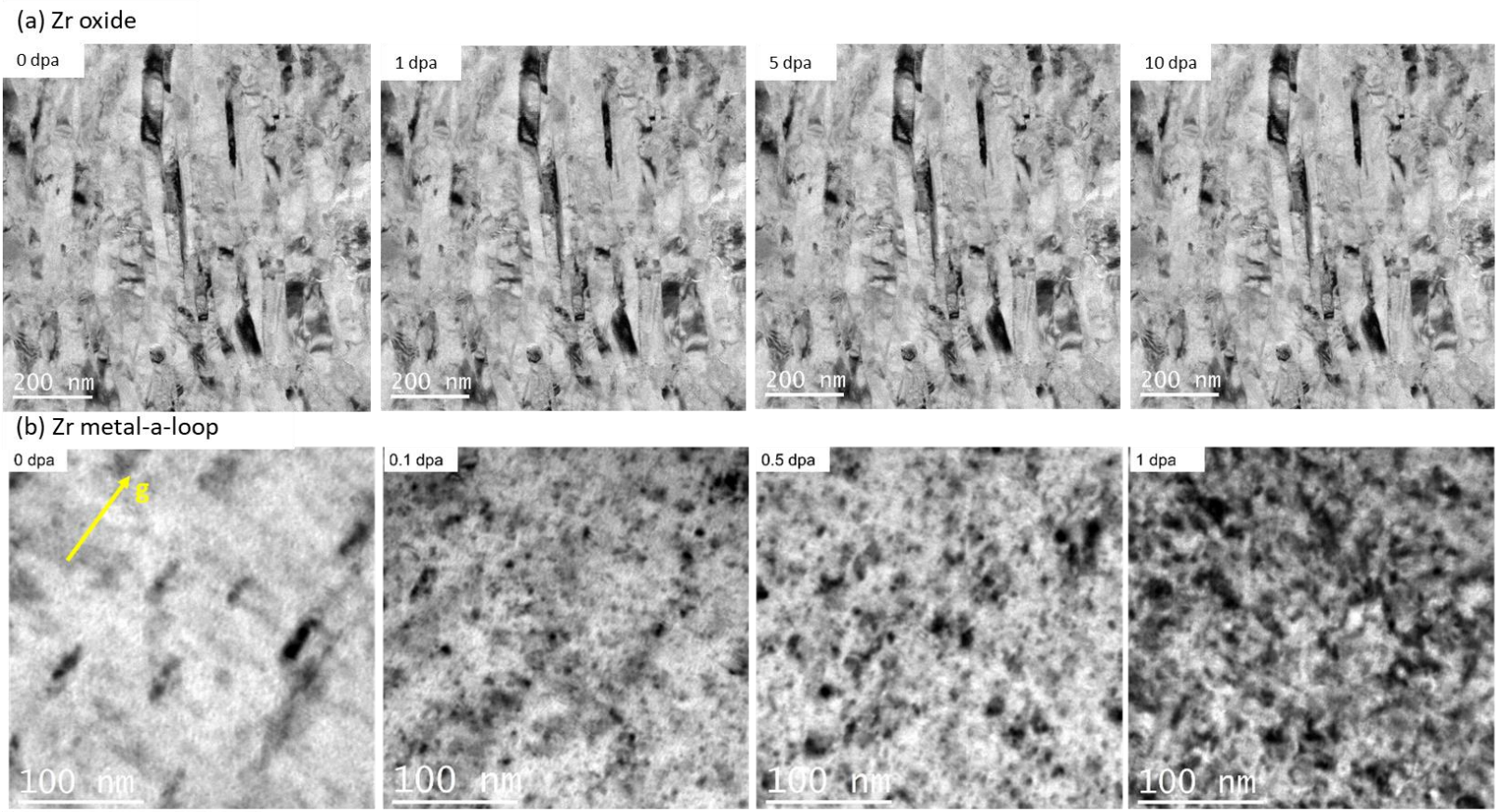

(c) Zr metal-c-loop
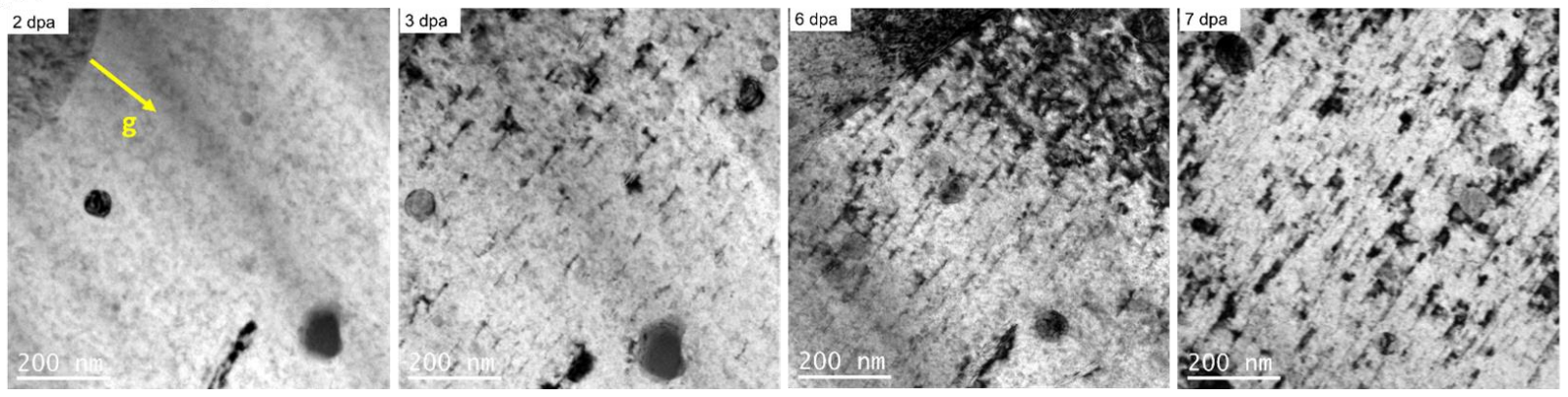
Figure 10: TEM BF images of damage generated dose in the recrystallised $\mathrm{Zr}-1.0 \mathrm{Nb}-0.1 \mathrm{Fe}$ sample after 360 days in the autoclave by in-situ ion irradiation with $1 \mathrm{MeV} \mathrm{Kr}^{2+}$ at $310{ }^{\circ} \mathrm{C}$. (a) Typical regions of the oxide structure up to $10 \mathrm{dpa}$. (b) <a> loop growth vs ion irradiation dose up to $1 \mathrm{dpa}$ with $\mathrm{g}=[01-10]$. (c) $<\mathrm{c}>$ loop growth vs ion irradiation dose up to 7 dpa with $\mathrm{g}=[0002]$.

\section{Discussion}

Before we discuss the results presented above on the microstructure and microchemistry of neutron-irradiated and autoclave samples, we will consider the effect of the different exposure temperatures in the two sets of samples. The neutron-irradiated samples developed $\sim 1.9 \mu \mathrm{m}$ of oxide in 540-days in a commercial PWR at a temperature estimated to lie between 305 and $315^{\circ} \mathrm{C}$, while the autoclave sample showed an oxide thickness of $\sim 5.2 \mu \mathrm{m}$ after 540 -days at $360{ }^{\circ} \mathrm{C}$.

The lower corrosion temperature for the in-reactor sample explains the apparent anomaly of the thinner oxide. Using an activation energy (Q) of $18000 \mathrm{cal} / \mathrm{K} / \mathrm{mol}[50]$ for $\mathrm{Zr}$ pre-transition oxidation kinetics, we estimate the oxide growth rate at $360^{\circ} \mathrm{C}(633 \mathrm{~K})$ should be 3.3 times faster than at $310^{\circ} \mathrm{C}(583 \mathrm{~K})$.

$$
\frac{t_{o x}(633 K)}{t_{o x}(583 K)}=\frac{B e^{-18000 / 633} t^{n}}{B e^{-18000 / 583} t^{n}}=3.3
$$

Using the measured oxide thickness of $5.2 \mu \mathrm{m}$ after 540 days of autoclave oxidation, we can then predict the oxide thickness after the same time at $310^{\circ} \mathrm{C}$ to be $1.57 \mu \mathrm{m}$, while we measure in the neutron-irradiated sample a thickness of $1.9 \mu \mathrm{m}$. This suggests for the particular samples studied here that in-reactor exposure show no serious evidence for radiation enhanced corrosion and are very likely to be still in pre-transition stage after 540 days. 
Previous studies on Sn-containing ZIRLO ${ }^{\circledR}$ and Zircaloys have shown that in-reactor exposure increases the rate of corrosion[51-55], but Zr-Nb alloys such as the Russian E110[56] and Areva M5TM [57] do not undergo accelerated corrosion in-reactor, especially when compared under PWR conditions with the performance of Zircaloy-4[57-59]. Thus we want to understand why it is the case by exploring the damage to the oxide and the metal matrix, SPP chemistry.

\subsection{Damage to the oxide}

There are many aspects of the complex oxide structures that can potentially influence the corrosion resistance of $\mathrm{Zr}$ alloys. Here we will first compare microstructural features like cracks, oxide grain morphology and porosity in the autoclave and in-reactor materials. The detailed microstructural analysis reported above shows that there are fewer cracks in the oxide formed in-reactor compared with the autoclave samples (Figures 1 and 2), whether we compare samples after the same total corrosion time or with the same oxide thickness. Similar observations have been reported on E110 samples[60]. Previous authors have suggested that there is a strong correlation between crack number density, corrosion rate and the time to transition[61], so this observation is consistent with the low corrosion rate of this $\mathrm{Zr}-\mathrm{Nb}$ alloy sample under irradiation comparing with the literature on Zircaloy-4 materials Zircaloy-4[57-59].

We have reported for the first time that a layer of vertical micro cracks can be formed on the top surface of the oxide on the in-reactor sample (Figure 2), and we have argued that they are not simply artefacts of the FIB sample preparation procedure as they are not present in all FIB-TEM samples and are visible in the bulk material before thinning. Some of these micro cracks develop into large penetrating cracks perpendicular to the metal-oxide interface, as shown by the example in Figure 2. This kind of perpendicular crack provides an obvious pathway for water penetration to accelerate the oxidation reaction, but in this particular case does not penetrate all the way down 
to the underlying metal or a region of thicker oxide would be formed under the crack as reported by Yardley et al[39].

The other obvious difference between the autoclave and in-reactor sample that might be relevant to the observation of fewer cracks in the in-reactor oxide is the high tetragonal grain fraction shown in Figure 4. It is particularly noticeable in the neutron irradiated sample that larger columnar tetragonal grains are present at the metal-oxide interface where stress is highest. It is important that $\mathrm{t}-\mathrm{ZrO} 2$ grains of this size have not been observed in any of the autoclave-oxidised samples in this or previous studies[62].

There are various reasons for higher tetragonal phase in the neutron irradiated materials:

First, this could be due to the compressive stress on the $\mathrm{m}-\mathrm{ZrO}^{2}$ generated by the collision cascades. Simeone et al[63,64] used Raman microprobe and grazing X-ray diffraction analysis to analyse $\mathrm{m}-\mathrm{ZrO}^{2}$ samples under irradiation by electrons and heavy ions, and showed an increasing tetragonal phase fraction after irradiation which they suggest is induced by compressive stress on the $\mathrm{m}-\mathrm{ZrO}^{2}$ generated by the collision cascades encouraging transition to the tetragonal phase. Similar observation is seen in proton irradiated Zircaloy-2[65]. Garner et al[65] studied neutron irradiated Zircaloy-2, revealed no extra stabilisation of the tetragonal grains which was attributed to the faster oxide growth and low total irradiation damage. This is not contradictory to our findings since $\mathrm{Zr}-1.0 \mathrm{Nb}$ has slower oxide growth than the Zircaloy-2 samples, so that longer total damage time in our $\mathrm{Zr}-1.0 \mathrm{Nb}$ gives enough time to introduce more tetragonal phase.

Second, this could be due to the stabilising effect of increasing impurities after irradiation. An early study by Adam[66] also suggested that increasing concentrations of impurities in the oxide may be linked to higher volume fractions of the tetragonal phase. Analysis of neutron irradiated 
Zircaloy-4 samples[67] showed that increasing Fe contents in the oxide may contribute to stabilisation of the tetragonal phase, and in this case the Fe may arise not only from radiationinduced dissolution of $\mathrm{Fe}$ from the $\mathrm{Zr}-\mathrm{Nb}-\mathrm{Fe}$ SPPs but also from dissolved Fe in the water.

Another contributing factor to controlling the overall oxidation rate in our samples could be porosity in the oxide[32], especially interconnected porosity of the type seen in the autoclave sample in Figure 5a. The oxide formed on the neutron-irradiated samples contains more equiaxed grains, as also reported on irradiated Zry-4[53,54], and significantly less porosity. The linear density of porosity near the metal-oxide interface is as low as $\sim 0.2 * 10^{-5} \mathrm{~nm} / \mathrm{nm}^{3}$ in the neutron irradiated sample, comparing with $\sim 0.7-1.5^{*} 10^{-5} \mathrm{~nm} / \mathrm{nm}^{3}$ in the autoclave oxidised samples. Together with the lack of cracks, this correlates well with the absence of accelerated corrosion rate in this irradiated sample[32].

Previous authors have also shown that there is $3 \%$ volume increase associated with the tetragonal to monoclinic phase transformation, and a reduction in the extent of this transformation could reduce the overall stress level and result in fewer microcracks, fewer nanoporosity and a more protective oxide film $[68,69]$. A combination of these mechanical and chemical effects may explain why the corrosion rate in the neutron irradiated sample studied here is only modestly accelerated.

Moving on to the $\mathrm{h}-\mathrm{ZrO}$ suboxide phases at the metal-oxide interface, we have previously shown a correlation between instantaneous oxidation rate and the thickness of the combined suboxide/oxygen-saturated area layer[70]. This feature of the metal-oxide interface can be best studied by STEM HAADF and scanning precession electron diffraction mapping in the TEM, as shown in Figure 4. The metal-oxide interface after neutron irradiation contains a complex mixture of fine suboxide grains and oxygen-saturated metal $(\operatorname{Zr}(\mathrm{Osat}))[4,41,71-73]$. The neutron irradiated sample has a much thinner suboxide layer, around $50-70 \mathrm{~nm}$, with some places having no 
detectable suboxide at all, and the oxygen-saturated layer is also very thin, around $50 \mathrm{~nm}$. Abolhassani et al[74,75] studied three different alloys (Zry-4, low tin ZIRLO® and Zr-2.5 Nb) and used EDX profiles across the metal-oxide interface to study oxygen diffusion profiles over distances greater than $200 \mathrm{~nm}$. Oxygen diffusion coefficients were measured of $6 \times 10^{-20} \mathrm{~m}^{2} \mathrm{~s}^{-1}$ for Zry-4 and $1 \times 10^{-20}$ and $0.8 \times 10^{-20} \mathrm{~m}^{2} \mathrm{~s}^{-1}$ for the more corrosion-resistant Nb-containing alloys[74,75]. Our observations on the interface phase distributions in the irradiated and autoclave samples are thus consistent with both the observed corrosion rates and the reduced oxygen diffusion rates in materials with this alloy chemistry. There is a lack of data in the literature reporting similar observations, however this shows neutron irradiation does not inhibit suboxide growth. The thinner suboxide thickness in the neutron irradiated sample than the autoclave one may be due to the fact that this sample is still in the early stage of suboxide growth, so that the Zr-O layer is still developing, however, its "barrier" effect is likely still existing. Further analysis on other neutron-irradiated samples at different exposure times is needed to answer this question.

\subsection{Damage to the metal matrix and SPP dissolution}

Moving onto the effect of irradiation, we have described an in-situ ion irradiation experiment in the TEM at $310^{\circ} \mathrm{C}$ showing that the oxide and suboxide layers are very stable, with no visible defects generated up to around $20 \mathrm{dpa}$ (Figure 10). It is often argued that neutron irradiation creates

point defects and voids, and hence enhances diffusivity of oxygen in the oxide[8,19,20,29] that will lead to an accelerated rate corrosion, but we see no evidence for void/crack formation. If the point defects in the oxide that cannot be seen in the TEM are readily absorbed at grain boundaries and other interfaces, the differences in oxide microstructure in the neutron irradiated sample and autoclave oxidised sample may be due to changes in the metal matrix rather than damage to the 
oxide film. This agrees with a previous study by Kammenzind[9] where they showed that oxide films grown on irradiated metal surfaces were similar in thickness and weight gain to those grown on irradiated, oxidised samples. If the metal matrix ultimately controls the corrosion rate after neutron irradiation, it is important to understand radiation-induced changes to the metal matrix and the SPPs.

Our results (Figures 7 and 9) show that the $\beta$-Nb SPPs remain stable after neutron irradiation, in agreement with studies on M5TM [57,72,76,77] and work on E110[25,78-80]. In both the autoclave and neutron-irradiated samples the SPPs oxidise gradually as they spend longer in the growing oxide, but the distribution of the $\mathrm{Nb}$ in these oxidised particles is similar in both materials. Several studies have focussed on radiation-induced precipitates (RIPs) in $\mathrm{Zr}-\mathrm{Nb}$ alloys[81,82], arguing that these RIPs are formed from the $\mathrm{Nb}$ in solid solution in the metal matrix, and that as the concentration of $\mathrm{Nb}$ falls in the metal matrix, better corrosion resistance is achieved. These authors also report that the $\mathrm{Nb}$ concentration in the $\beta$-Nb SPPs drops from $85 \%$ to $55 \%$ after irradiation[81], providing another source of excess $\mathrm{Nb}$. In our samples we observed RIPs in the neutron-irradiated sample but not after ion-irradiation, possibly due to the high dose rate in in-situ ion irradiation using heavy ions such as $\mathrm{Kr}$ under the TEM with damage rate around $0.001 \mathrm{dpa} / \mathrm{s}$. This will create high concentrations of point defects that will enhance the rate of solute diffusion within the matrix so displaced $\mathrm{Nb}$ atoms can quickly return to their equilibrium state in the SPPs[83]. A key fact that is missing in developing an understanding of the RIP phenomenon in these alloys is accurate data on the concentration of $\mathrm{Nb}$ in metastable solid solution in the irradiated metal matrix that will require the use of techniques such as APT[28].

From the EDX mapping results on the neutron-irradiated sample, it is clear that Fe is displaced from the Zr-Nb-Fe SPPs at higher rates than $\mathrm{Cr}$ (Figure 7 and Figure 9). Lefebvre et al[53] 
suggested that the redistribution of $\mathrm{Fe}$ is associated with preferential oxidation of $\mathrm{Zr}(\mathrm{Fe}, \mathrm{Cr})_{2} \mathrm{SPPs}$, and argued that the release of Fe can have a chemical stabilisation effect on the tetragonal phase. However, in the $\mathrm{Zr}-1.0 \mathrm{Nb}$ alloys studied here, these Fe-containing SPPs remain metallic near the metal-oxide interface (Figure 6 and Figure 7). The higher tetragonal phase fraction in the oxide on the neutron-irradiated sample may be a result of stress-stabilisation near the metal-oxide interface and stabilisation by displaced Fe deeper into the oxide layer.

Another effect of Fe redistribution from the SPPs can be to change the local charge state by doping the oxide with $\mathrm{Fe} 2+/ 3+$ ions on $\mathrm{Zr} 4+$ sites, and reducing the build up of space charge[11]. XANES studies[84] on $\mathrm{Zr}-2.5 \mathrm{Nb}$ alloys have shown that the $\mathrm{Nb}$ and $\mathrm{Fe}$ in solid solution in the oxide, and incorporated in the SPPs showed delayed oxidation (4+, 2+ stage), comparing with the 5+ Nb full oxidation stage. However, regarding the extent of the Fe contribution to space charge compensation, it is important to note that not all the Fe in solid solution is immediately oxidised when the matrix is oxidised because there is experimental evidence from EELS analysis for metallic Fe in the innermost part of the oxide, indicating that Fe exhibits a delayed oxidation behaviour.

\subsection{Illustrations of reactor corrosion vs autoclave corrosion in Zr-1.0Nb alloys}

Figure 11 illustrates the differences between reactor corrosion and autoclave corrosion in $\mathrm{Zr}-1.0 \mathrm{Nb}$ alloys and explains the no irradiation enhanced corrosion in the $\mathrm{Zr}-1.0 \mathrm{Nb}$ alloys:

Before irradiation: the $\mathrm{Zr}-1.0 \mathrm{Nb}$ alloys consists of equiaxed metal grains with both $\beta-\mathrm{Nb}$ and $\mathrm{Zr}-$ $\mathrm{Nb}-\mathrm{Fe}$ precipitates.

Reactor corrosion: A higher volume fraction of tetragonal oxide was found in the neutron irradiated sample, indicating less tetragonal to monoclinic transition, which leads to fewer cracks 
and less porosity, thus more protective oxide. Tetragonal oxide can be 1) stabilised by irradiation, 2) stabilised by local release of impurity species from SPPs such as dissolution of Fe from $\mathrm{Zr}-\mathrm{Nb}$ Fe precipitates or radiation introduced precipitates (RIPs) which is likely to be small $\beta$-Nb clusters. As oxide continues to grow, there are more and more $\langle\mathrm{a}\rangle$ and $\langle\mathrm{c}\rangle$ loops, Fe dissolved from the SPP and RIPs in the metal matrix, which introduces some cracks and forms less organised oxide grains. However, the corrosion rate is low enough, for the tetragonal oxide to stabilise and suboxide $+\mathrm{Zr}$ (Osat) phases exist for long time, so there is no enhanced corrosion after irradiation.

Autoclave corrosion: Given there is no irradiation or not enough local release of impurity species from SPPs to stabilise tetragonal phase, tetragonal to monoclinic transition happens, forms micro cracks and nano-porosity in the oxide film, also more organised equiaxed-colomnar-equiaxed grain structure and less tetragonal phase fraction. Transition happens when local stress at the metaloxide interface reaches limit and forms a layer of transition cracks, oxidation rate increases, suboxide is rapidly consumed and corrosion rate increases.


Figure 11: Illustrations of reactor corrosion vs autoclave corrosion in $\mathrm{Zr}-1.0 \mathrm{Nb}$ alloys: (a) before irradiation: equiaxed metal grains with both $\beta-\mathrm{Nb}$ and $\mathrm{Zr}-\mathrm{Nb}-\mathrm{Fe}$ precipitates; (b) reactor corrosion: 
(b-1) a higher volume fraction of tetragonal oxide is formed due to the stabilisation effects of $<a>$ and $<\mathrm{c}>$ loops, or local release of impurity species from SPPs such as dissolution of $\mathrm{Fe}$ out of $\mathrm{Zr}$ Fe-Nb SPP and RIPs in the metal matrix, (b-2) over time, there is less tetragonal to monoclinic transition, which leads to fewer cracks and less porosity, thus more protective oxide with stable $\mathrm{ZrO}$ suboxide and $\mathrm{Zr}$ (Osat) layers; (c) autoclave corrosion: (c-1), more organised equiaxedcolomnar-equiaxed grain structure is formed with less tetragonal phase, (c-2) over time, tetragonal to monoclinic transition happens, forms micro cracks and nano-porosity in the oxide film, suboxide is rapidly consumed and corrosion rate increases, transition happens.

\section{Conclusions}

A detailed study using a range of advanced microscopy techniques has been carried out on recrystallised $\mathrm{Zr}-1.0 \mathrm{Nb}$ alloys under three conditions; autoclave oxidised, neutron irradiated inreactor and in situ ion irradiated in the TEM.

After 540 days in reactor with an estimated fast neutron fluence of $4.35 \times 10^{25} \mathrm{n} / \mathrm{m}^{2}, \mathrm{E}>1 \mathrm{MeV}$, and around $5 \mathrm{dpa}$, the neutron irradiated sample has uniform oxide thickness of $\sim 1.9 \mu \mathrm{m}$ while the same material in the autoclave for 120 days has a $2.2 \mu$ m oxide and after 540 days a $5.2 \mu$ m oxide. Correcting for the lower in-flux temperature $\left(310^{\circ} \mathrm{C}\right)$ than the autoclave temperature $\left(360^{\circ} \mathrm{C}\right)$, these $\mathrm{Zr}-\mathrm{Nb}$ alloys show no serious evidence for radiation enhanced corrosion[57-59] and are very likely to be still in pre-transition stage after 540 days.

The good corrosion resistance of the neutron irradiated $\mathrm{Zr}-1.0 \mathrm{Nb}$ can be related to the higher volume fraction of tetragonal oxide, fewer interconnected nano porosity/ cracks in the oxide. This indicates less tetragonal to monoclinic transition, leads to more protective oxide in the neutron irradiated sample, containing little evidence for short circuit paths for the penetration of oxygen or 
water towards the metal-oxide interface. The linear density of porosity at the protective layer is as small as $\sim 0.2 * 10^{-5} \mathrm{~nm} / \mathrm{nm}^{3}$ in the neutron irradiated sample, comparing with $\sim 0.7-1.5^{*} 10^{-5}$ $\mathrm{nm} / \mathrm{nm}^{3}$ in the autoclave oxidised samples. These observations on a sample with a slow overall oxidation rate are consistent with the hypothesis that interconnected porosity can lead to early transitions and rapid oxidation.

The oxide consists of well-aligned columnar-equiaxed microstructure in the autoclave sample while a more complex oxide grain structure was observed in the neutron-irradiated sample. As oxide continues to grow, there are more $\langle a\rangle$ and $\langle\mathrm{c}\rangle$ loops, dissolved Fe and RIPs in the metal matrix, however, the corrosion rate is low enough for the tetragonal oxide to stabilise and suboxide $+\mathrm{Zr}$ (Osat) phases exist for protectiveness, so there is no enhanced corrosion after irradiation.

Tetragonal oxide can be either stabilised by irradiation, or stabilised by local release of impurity species from SPPs such as dissolution of Fe from $\mathrm{Zr}-\mathrm{Nb}-\mathrm{Fe}$ precipitates or radiation introduced precipitates (RIPs) which is likely to be small $\beta$ - Nb clusters. In situ ion irradiation in the TEM revealed no visible defect clusters or voids in the oxide, suggesting that radiation damage to the metal matrix may have a stronger effect of corrosion mechanisms during neutron irradiation. Dislocation loops are the main defects produced in the metal matrix during irradiation with both neutrons and ions, and $\langle\mathrm{a}\rangle$ and then $\langle\mathrm{c}\rangle$ loops grow under increasing ion irradiation dose. The linear density and size of the $<c>$ loops is slightly smaller in the neutron-irradiated sample than in the ion-irradiated sample after the same dpa. Neutron irradiation seems to have little effect on promoting either faster oxidation or dissolution of $\beta-\mathrm{Nb}$ precipitates, but may encourage dissolution of Fe from $\mathrm{Zr}-\mathrm{Nb}-\mathrm{Fe}$ precipitates. Radiation introduced precipitates appear in the $\mathrm{Zr}$ matrix after 5 dpa of neutron damage, but are not observed after ion irradiation. 


\section{Acknowledgements}

This work was undertaken as part of the MUZIC-2 collaboration studying oxidation and hydrogen pickup in Zr alloys. The authors gratefully acknowledge support from EDF, Westinghouse, EPRI and Rolls Royce, and many useful discussions within the consortium. The authors would like to thank Pete Baldo and Ed Ryan at the Argonne National Laboratory for their help during the in-situ TEM experiments, and use of the IVEM-Tandem facility was supported by the U.S. Department of Energy, Office of Nuclear Energy under DOE Idaho Operations Office Contract DE-AC07051D14517 as part of a Nuclear Science User Facilities experiment. Use of the Center for Nanoscale Materials, an Office of Science user facility, was supported by the U.S. Department of Energy, Office of Science, Office of Basic Energy Sciences, under Contract No. DE-AC0206CH11357. UK EPSRC grant EP/K040375/1 is acknowledged for funding the South of England Analytical Electron Microscope

\section{References}

[1] M. Zhernenkov, S. Gill, V. Stanic, E. DiMasi, K. Kisslinger, J.K. Baldwin, A. Misra, M.J. Demkowicz, L. Ecker, Design of radiation resistant metallic multilayers for advanced nuclear systems, Appl. Phys. Lett. 104 (2014) 241906. doi:10.1063/1.4883481.

[2] D.R. Olander, A.T. Motta, Zirconium Alloys, in: Light Water React. Mater., 1999: pp. 139.

[3] A. Garner, J. Hu, A. Harte, P. Frankel, C. Grovenor, S. Lozano-Perez, M. Preuss, The effect of Sn concentration on oxide texture and microstructure formation in zirconium alloys, Acta Mater. 99 (2015) 259-272. doi:10.1016/J.ACTAMAT.2015.08.005.

[4] J. Hu, A. Garner, N. Ni, A. Gholinia, R.J. Nicholls, S. Lozano-Perez, P. Frankel, M. Preuss, C.R.M. Grovenor, Identifying suboxide grains at the metal-oxide interface of a corroded $\mathrm{Zr}-1.0 \% \mathrm{Nb}$ alloy using (S)TEM, transmission-EBSD and EELS, Micron. 69 (2015) 35-42. doi:10.1016/j.micron.2014.10.004.

[5] J. Romero, J. Partezana, R.J. Comstock, L. Hallstadius, Evolution of Hydrogen Pickup Fraction with Oxidation Rate on Zirconium Alloys, TopFuel 2015. (2015) 1-7.

[6] J. Wei, P. Frankel, M. Blat, a Ambard, R.J. Comstock, L. Hallstadius, S. Lyon, R. a 
Cottis, M. Preuss, Autoclave study of zirconium alloys with and without hydride rim, Corros. Eng. Sci. Technol. 47 (2012) 516-528. doi:10.1179/1743278212Y.0000000055.

[7] V.F. Urbanic, B.D. Warr, A. Manolescu, C.K. Chow, M.W. Shanahan, Oxidation and Deuterium Uptake of Zr-2.5Nb Pressure Tubes in CANDU-PHW Reactors, Eighth Int. Symp. Zircon. Nucl. Ind. STP 1023 (1989) 20-34. doi:10.1520/STP18855S.

[8] B. Cox, Some thoughts on the mechanisms of in-reactor corrosion of zirconium alloys, J. Nucl. Mater. 336 (2005) 331-368. doi:10.1016/j.jnucmat.2004.09.029.

[9] B.F. Kammenzind, J.A. Gruber, R. Bajaj, J.D. Smee, Neutron Irradiation Effects on the Corrosion of Zircaloy-4 in a PWR Environment, ASTM Zr. (2016).

[10] F. Garzarolli, B. Cox, P. Rudling, ANT International Report: Corrosion and Hydriding, Mölnlycke, 2012.

[11] A. Couet, A.T. Motta, A. Ambard, The coupled current charge compensation model for zirconium alloy fuel cladding oxidation: I. Parabolic oxidation of zirconium alloys, Corros. Sci. 100 (2015) 73-84. doi:10.1016/J.CORSCI.2015.07.003.

[12] N. Ni, D. Hudson, J. Wei, P. Wang, S. Lozano-Perez, G.D.W. Smith, J.M. Sykes, S.S. Yardley, K.L. Moore, S. Lyon, R. Cottis, M. Preuss, C.R.M. Grovenor, How the crystallography and nanoscale chemistry of the metal/oxide interface develops during the aqueous oxidation of zirconium cladding alloys, Acta Mater. 60 (2012) 7132-7149. doi:10.1016/j.actamat.2012.09.021.

[13] R.J. Nicholls, N. Ni, S. Lozano-Perez, A. London, D.W. Mccomb, P.D. Nellist, C.R.M. Grovenor, C.J. Pickard, J.R. Yates, Crystal Structure of the ZrO Phase at Zirconium/Zirconium Oxide Interfaces, Adv. Eng. Mater. 17 (2015). doi:10.1002/adem.201400133.

[14] N. Ni, S. Lozano-Perez, M.L. Jenkins, C. English, G.D.W. Smith, J.M. Sykes, C.R.M. Grovenor, Porosity in oxides on zirconium fuel cladding alloys, and its importance in controlling oxidation rates, Scr. Mater. 62 (2010) 564-567.

doi:10.1016/J.SCRIPTAMAT.2009.12.043.

[15] R.B. Adamson, M. Griffiths, Microstructure Evolution in Zr Alloys during Irradiation: Dose, Dose Rate, and Impurity Dependence, in: Zircon. Prod. Technol. Kroll Medal Pap. 1975-2010, ASTM International, 100 Barr Harbor Drive, PO Box C700, West Conshohocken, PA 19428-2959, 2010: pp. 429-429-10. doi:10.1520/MNL12126R.

[16] M. Griffiths, J. Mecke, J. Winegar, Evolution of Microstructure in Zirconium Alloys During Irradiation, in: Zircon. Nucl. Ind. Elev. Int. Symp., ASTM International, 100 Barr Harbor Drive, PO Box C700, West Conshohocken, PA 19428-2959, 1996: pp. 580-58023. doi:10.1520/STP16191S.

[17] M. Griffiths, A review of microstructure evolution in zirconium alloys during irradiation, J. Nucl. Mater. 159 (1988) 190-218. doi:10.1016/0022-3115(88)90093-1.

[18] P. Bossis, D. Pe^cheur, K. Hanifi, J. Thomazet, M. Blat, S. Dean, Comparison of the High Burn-Up Corrosion on M5 and Low Tin Zircaloy-4, J. ASTM Int. 3 (2006) 12404. doi:10.1520/JAI12404. 
[19] S. Abolhassani, R. Restani, T. Rebac, F. Groeschel, W. Hoffelner, G. Bart, W. Goll, F. Aeschbach, TEM Examinations of the Metal-Oxide Interface of Zirconium Based Alloys Irradiated in a Pressurized Water Reactor, J. ASTM Int. 2 (2005) 12390.

doi:10.1520/JAI12390.

[20] X. Iltis, F. Lefebvre, C. Lemaignan, Microstructural study of oxide layers formed on Zircaloy-4 in autoclave and in reactor part 11: Impact of the chemical evolution of intermetallic precipitates on their zirconia environment, J. Nucl. Mater. 224 (1995) 121130. doi:10.1016/0022-3115(95)00069-0.

[21] R.M. Hengstler-Eger, P. Baldo, L. Beck, J. Dorner, K. Ertl, P.B. Hoffmann, C. Hugenschmidt, M.A. Kirk, W. Petry, P. Pikart, A. Rempel, Heavy ion irradiation induced dislocation loops in AREVA's M5® alloy, J. Nucl. Mater. 423 (2012) 170-182. doi:10.1016/j.jnucmat.2012.01.002.

[22] Y. Idrees, Z. Yao, M.A. Kirk, M.R. Daymond, In situ study of defect accumulation in zirconium under heavy ion irradiation, J. Nucl. Mater. 433 (2013) 95-107. doi:10.1016/j.jnucmat.2012.09.014.

[23] L.L. Sylvie Doriot, Didier Gilbon, Jean-Luc Béchade, Marie-Hélène Mathon, and J.-P. Mardon, Microstructural Stability of M5TM Alloy Irradiated up to High Neutron Fluences, Zircon. Nucl. Ind. Fourteenth Int. Symp. ASTM STP 1467 175-204. (n.d.).

[24] J.P. Gilbon, D., Soniak, A., Doriot, S., and Mardon, Irradiation Creep and Growth Behaviour, and Microstructural Evolution of Advanced Zr-Base Alloys, Zircon. Nucl. Ind. Twelfth Int. Symp. ASTM STP 1354. (n.d.).

[25] V.N. Shishov, M.M. Peregud, A. V Nikulina, G.P. Kobylyansky, A.E. Novoselov, Z.E. Ostrovsky, A. V Obukhov, Influence of Structure - Phase State of Nb Containing Zr Alloys on Irradiation-Induced Growth, in: Zircon. Nucl. Ind. Fourteenth Int. Symp., ASTM International, 2005: pp. 666-685. doi:10.1520/JAI12431.

[26] V.N. Shishov, The Evolution of Microstructure and Deformation Stability in $\mathrm{Zr}-\mathrm{Nb}-$ (Sn,Fe) Alloys Under Neutron Irradiation, in: Zircon. Nucl. Ind. 16th Int. Symp., ASTM International, 100 Barr Harbor Drive, PO Box C700, West Conshohocken, PA 194282959, 2012: pp. 37-66. doi:10.1520/STP152920120003.

[27] V. Shishov, A. Nikulina, V. Markelov, M. Peregud, A. Kozlov, S. Averin, S. Kolbenkov, A. Novoselov, Influence of Neutron Irradiation on Dislocation Structure and Phase Composition of Zr-Base Alloys, in: Zircon. Nucl. Ind. Elev. Int. Symp., ASTM International, 100 Barr Harbor Drive, PO Box C700, West Conshohocken, PA 194282959, 1996: pp. 603-603-20. doi:10.1520/STP16192S.

[28] G. Sundell, M. Thuvander, P. Tejland, M. Dahlbäck, L. Hallstadius, H.-O. Andrén, Redistribution of alloying elements in Zircaloy-2 after in-reactor exposure, J. Nucl. Mater. 454 (2014) 178-185. doi:10.1016/J.JNUCMAT.2014.07.072.

[29] C. Lemaignan, Physical Phenomena Concerning Corrosion Under Irradiation of Zr Alloys, in: Zircon. Nucl. Ind. Thirteen. Int. Symp., ASTM International, 100 Barr Harbor Drive, PO Box C700, West Conshohocken, PA 19428-2959, 2002: pp. 20-20-10. doi:10.1520/STP11381S. 
[30] J. Hu, B. Setiadinata, T. Aarholt, A. Garner, A. Vilalta-clemente, P. Frankel, P. Bagot, S. Lozano-perez, A. Wilkinson, M. Preuss, High-resolution characterization of Zr nuclear fuel cladding alloys, in: 18th Int. Symp. Zircon. Nucl. Ind., 2016.

[31] J. Hu, B. Setiadinata, T. Aarholt, P. Bagot, M. Moody, C. Grovenor, A. Garner, A. Harte, K. Moore, P. Frankel, M. Preuss, N. Ni, High-resolution characterization of corrosion and hydrogen pickup of Zr cladding alloys, TopFuel 2015. (2015).

[32] N. Ni, S. Lozano-Perez, M.L. Jenkins, C. English, G.D.W. Smith, J.M. Sykes, C.R.M. Grovenor, Porosity in oxides on zirconium fuel cladding alloys, and its importance in controlling oxidation rates, Scr. Mater. 62 (2010) 564-567. doi:10.1016/j.scriptamat.2009.12.043.

[33] M. Kirk, X. Yi, M. Jenkins, Characterization of irradiation defect structures and densities by transmission electron microscopy, J. Mater. Res. 30 (2015) 1195-1201.

doi:10.1557/jmr.2015.19.

[34] R.E. Stoller, M.B. Toloczko, G.S. Was, A.G. Certain, S. Dwaraknath, F.A. Garner, On the use of SRIM for computing radiation damage exposure, Nucl. Instruments Methods Phys. Res. Sect. B Beam Interact. with Mater. Atoms. 310 (2013) 75-80. doi:10.1016/j.nimb.2013.05.008.

[35] J. Ziegler, James Ziegler - SRIM \& TRIM - http://www.srim.org/, (n.d.). http://www.srim.org/ (accessed January 16, 2018).

[36] A. Yilmazbayhan, E. Breval, A.T. Motta, R.J. Comstock, Transmission electron microscopy examination of oxide layers formed on $\mathrm{Zr}$ alloys, J. Nucl. Mater. 349 (2006) 265-281. doi:10.1016/j.jnucmat.2005.10.012.

[37] A.T. Motta, M.J. Gomes da Silva, A. Yilmazbayhan, R.J. Comstock, Z. Cai, B. Lai, M. Limback, B. Kammenzind, S.W. Dean, Microstructural Characterization of Oxides Formed on Model Zr Alloys Using Synchrotron Radiation, J. ASTM Int. 5 (2008) 101257. doi:10.1520/JAI101257.

[38] N. Ni, Study of Oxidation Mechanisms of Zirconium Alloys by Electron Microscopy, 2011.

[39] S.S. Yardley, K.L. Moore, N. Ni, J.F. Wei, S. Lyon, M. Preuss, S. Lozano-Perez, C.R.M. Grovenor, An investigation of the oxidation behaviour of zirconium alloys using isotopic tracers and high resolution SIMS, J. Nucl. Mater. 443 (2013) 436-443. doi:10.1016/j.jnucmat.2013.07.053.

[40] J. Hu, B. Setiadinata, T. Aarholt, P. Bagot, M. Moody, C. Grovenor, A. Garner, A. Harte, K. Moore, P. Frankel, M. Preuss, Role of barrier layer in $\mathrm{Zr}$ corrosion and hydrogen pickup: Part I- nano-porosity in recrystallised and annealed $\mathrm{Zr}-1.0 \mathrm{Nb}$, (n.d.).

[41] N. Ni, D. Hudson, J. Wei, P. Wang, S. Lozano-Perez, G.D.W. Smith, J.M. Sykes, S.S. Yardley, K.L. Moore, S. Lyon, R. Cottis, M. Preuss, C.R.M. Grovenor, How the crystallography and nanoscale chemistry of the metal/oxide interface develops during the aqueous oxidation of zirconium cladding alloys, Acta Mater. 60 (2012) 7132-7149. doi:10.1016/j.actamat.2012.09.021. 
[42] H.G. Kim, Y.H. Jeong, T.H. Kim, Effect of isothermal annealing on the corrosion behavior of Zr-xNb alloys, J. Nucl. Mater. 326 (2004) 125-131.

doi:10.1016/j.jnucmat.2004.01.015.

[43] C. Toffolon-Masclet, J.-C. Brachet, G. Jago, Studies of second phase particles in different zirconium alloys using extractive carbon replica and an electrolytic anodic dissolution procedure, J. Nucl. Mater. 305 (2002) 224-231. doi:10.1016/S0022-3115(02)00911-X.

[44] J. Hu, B. Setiadinata, T. Aarholt, A. Garner, A. Vilalta-clemente, J.M. Partezana, P. Frankel, P. Bagot, S. Lozano-perez, A. Wilkinson, M. Preuss, M. Moody, C. Grovenor, Understanding Corrosion and Hydrogen Pickup of Zirconium Fuel Cladding Alloys: The Role of Oxide Microstructure, Porosity, Suboxides, and Second-Phase Particles, 2018. doi:10.1520/STP159720160071.

[45] M. Griffiths, R.W. Gilbert, G.J.C. Carpenter, Phase instability, decomposition and redistribution of intermetallic precipitates in Zircaloy-2 and -4 during neutron irradiation, J. Nucl. Mater. 150 (1987) 53-66. doi:10.1016/0022-3115(87)90093-6.

[46] W.J.S. Yang, R.P. Tucker, B. Cheng, R.B. Adamson, Precipitates in zircaloy: Identification and the effects of irradiation and thermal treatment, J. Nucl. Mater. 138 (1986) 185-195. doi:10.1016/0022-3115(86)90005-X.

[47] E.M. Francis, A. Harte, P. Frankel, S.J. Haigh, D. J??dern??s, J. Romero, L. Hallstadius, M. Preuss, Iron redistribution in a zirconium alloy after neutron and proton irradiation studied by energy-dispersive X-ray spectroscopy (EDX) using an aberration-corrected (scanning) transmission electron microscope, J. Nucl. Mater. 454 (2014) 387-397. doi:10.1016/j.jnucmat.2014.08.034.

[48] W.Z. Han, M.J. Demkowicz, E.G. Fu, Y.Q. Wang, A. Misra, Effect of grain boundary character on sink efficiency, Acta Mater. 60 (2012) 6341-6351. doi:10.1016/J.ACTAMAT.2012.08.009.

[49] L. Jiao, A. Chen, M.T. Myers, M.J. General, L. Shao, X. Zhang, H. Wang, Enhanced ion irradiation tolerance properties in TiN/MgO nanolayer films, J. Nucl. Mater. 434 (2013) 217-222. doi:10.1016/j.jnucmat.2012.11.034.

[50] D.L. Douglass, Corrosion mechanism of zirconium and its alloys- Diffusion of oxygen in zirconium dioxide, Rep. GEAP-3999, U.S. At. Energy Comm. 1 (1962).

[51] T. Kido, K. Kanasugi, M. Sugano, K. Komatsu, PWR Zircaloy cladding corrosion behavior : quantitative analyses, J. Nucl. Mater. 248 (1997) 281-287. doi:10.1016/S00223115(97)00125-6.

[52] S. Shimada, Y. Etoh, K. Tomida, BWR Zircaloy cladding corrosion behavior - effect of microstructure, J. Nucl. Mater. 248 (1997) 275-280. doi:10.1016/S0022-3115(97)001244.

[53] F. Lefebvre, C. Lemaignan, Irradiation effects on corrosion of zirconium alloy claddings, J. Nucl. Mater. 248 (1997) 268-274. doi:10.1016/S0022-3115(97)00123-2.

[54] X. Iltis, F. Lefebvre, C. Lemaignan, Microstructure Evolution and Iron Redistribution in Zircaloy Oxide Layers: Comparative Effects of Neutron Irradiation Flux and Irradiation 
Damages, in: 11th Int. Symp. Zircon. Nucl. Ind., ASTM International, 100 Barr Harbor Drive, PO Box C700, West Conshohocken, PA 19428-2959, 1996: pp. 242-264. doi:10.1520/STP16176S.

[55] C. Yan, R. Wang, Y. Wang, X. Wang, G. Bai, Effects of ion irradiation on microstructure and properties of zirconium alloys-A review, Nucl. Eng. Technol. 47 (2015) 323-331. doi:10.1016/j.net.2014.12.015.

[56] A.P. and A.O.S.S.R. V. Markelov, V. Novikov, A. Gusev, A. Shevyakov, M Peregud and V. Konkov, S. Eremin, Preliminary Irradiation Effect on Corrosion Resistance of Zirconium Alloys, Zircon. Nucl. Ind. - 18th Int. Symp. (n.d.).

[57] A.D. Joël THOMAZET, J.G. Philippe BOSSIS, A.M. Martine BLAT, The corrosion of the alloy M5TM: an overview, IAEA Tech. Comm. Meet. Behav. High Corros. Zr-Based Alloy. Buenos Aires. (n.d.).

[58] P. Bossis, B. Verhaeghe, S. Doriot, D. Gilbon, V. Chabretou, A. Dalmais, J.-P. Mardon, M. Blat, A. Miquet, In PWR Comprehensive Study of High Burn-Up Corrosion and Growth Behavior of M5® and Recrystallized Low-Tin Zircaloy-4, in: Zircon. Nucl. Ind. 15th Int. Symp., ASTM International, 100 Barr Harbor Drive, PO Box C700, West Conshohocken, PA 19428-2959, 2009: pp. 430-430-27. doi:10.1520/STP48148S.

[59] E. Hillner, Corrosion of Zirconium-Base Alloys-An Overview, in: Zircon. Nucl. Ind., ASTM International, 100 Barr Harbor Drive, PO Box C700, West Conshohocken, PA 19428-2959, 1977: pp. 211-211-25. doi:10.1520/STP35573S.

[60] A.O. A. Shevyakov, V. Novikov, V. Markelov, G. Kobylyansky, Study of Structure-Phase State of Oxide Films on E110 and E635 Alloys at Pre- and PostIrradiation Stages, Zircon. Nucl. Ind. - 18th Int. Symp. (n.d.).

[61] A. Yilmazbayhan, A.T. Motta, R.J. Comstock, G.P. Sabol, B. Lai, Z. Cai, Structure of zirconium alloy oxides formed in pure water studied with synchrotron radiation and optical microscopy: relation to corrosion rate, J. Nucl. Mater. 324 (2004) 6-22. doi:10.1016/J.JNUCMAT.2003.08.038.

[62] A. Garner, J. Hu, A. Harte, P. Frankel, C. Grovenor, S. Lozano-Perez, M. Preuss, The effect of Sn concentration on oxide texture and microstructure formation in zirconium alloys, Acta Mater. 99 (2015) 259-272. doi:10.1016/J.ACTAMAT.2015.08.005.

[63] D. Simeone, J.L. Bechade, D. Gosset, A. Chevarier, P. Daniel, H. Pilliaire, G. Baldinozzi, Investigation on the zirconia phase transition under irradiation, J. Nucl. Mater. 281 (2000) 171-181. doi:10.1016/S0022-3115(00)00183-5.

[64] D. Simeone, D. Gosset, J.L. Bechade, A. Chevarier, Analysis of the monoclinic-tetragonal phase transition of zirconia under irradiation, J. Nucl. Mater. 300 (2002) 27-38. doi:10.1016/S0022-3115(01)00701-2.

[65] A. Garner, F. Baxter, P. Frankel, M. Topping, A. Harte, T. Slater, P. Tejland, J.E. Romero, E.C. Darby, Investigating the Effect of Zirconium Oxide Microstructure on Corrosion Performance : A Comparison between Neutron , Proton, and Nonirradiated Oxides, (2018) 491-523. doi:10.1520/STP159720160069. 
[66] J. Adam, B. Cox, Neutron and Fission Fragment Damage in Zirconia, Phys. Rev. Lett. 3 (1959) 543-544. doi:10.1103/PhysRevLett.3.543.

[67] X. Iltis, F. Lefebvre, C. Lemaignan, Microstructural study of oxide layers formed on Zircaloy-4 in autoclave and in reactor part II: Impact of the chemical evolution of intermetallic precipitates on their zirconia environment, J. Nucl. Mater. 224 (1995) 121130. doi:10.1016/0022-3115(95)00069-0.

[68] A. Garner, M. Preuss, P. Frankel, IUCr, A method for accurate texture determination of thin oxide films by glancing-angle laboratory X-ray diffraction, J. Appl. Crystallogr. 47 (2014) 575-583. doi:10.1107/S1600576714000569.

[69] J. Wei, P. Frankel, E. Polatidis, M. Blat, A. Ambard, R.J. Comstock, L. Hallstadius, D. Hudson, G.D.W. Smith, C.R.M. Grovenor, M. Klaus, R.A. Cottis, S. Lyon, M. Preuss, The effect of Sn on autoclave corrosion performance and corrosion mechanisms in $\mathrm{Zr}-\mathrm{Sn}-$ Nb alloys, Acta Mater. 61 (2013) 4200-4214.

[70] J. Hu, B. Setiadinata, T. Aarholt, A. Garner, A. Vilalta-clemente, J.M. Partezana, P. Frankel, P. Bagot, S. Lozano-perez, A. Wilkinson, M. Preuss, M. Moody, C. Grovenor, Understanding Corrosion and Hydrogen Pickup of Zirconium Fuel Cladding Alloys: The Role of Oxide Microstructure, Porosity, Suboxides, and Second-Phase Particles, Zircon. Ind. 18Th Int. Symp. (2018) 93-126. doi:10.1520/STP159720160071.

[71] N. Ni, S. Lozano-Perez, J. Sykes, C. Grovenor, Quantitative EELS analysis of zirconium alloy metal/oxide interfaces., Ultramicroscopy. 111 (2011) 123-30.

doi:10.1016/j.ultramic.2010.10.020.

[72] P. Bossis, Multi-Scale Characterization of the Metal-Oxide Interface of Zirconium Alloys, 12th Int. Symp. Zircon. Nucl. Ind. (2000) 918-945.

[73] N. Ni, S. Lozano-Perez, J. Sykes, C. Grovenor, Transmission EELS Quantification Study of Oxygen Content at Zirconium Alloy Metal/Oxide Interface, Microsc. Microanal. 16 (2010) 1614-1615. doi:10.1017/S1431927610054000.

[74] S. Abolhassani, R. Restani, T. Rebac, F. Groeschel, W. Hoffelner, G. Bart, W. Goll, A. F, Zirconium in the nuclear industry 14, ASTM International, 2005. doi:10.1520/JAI12390.

[75] S. Abolhassani, G. Bart, A. Jakob, Examination of the chemical composition of irradiated zirconium based fuel claddings at the metal/oxide interface by TEM, J. Nucl. Mater. 399 (2010) 1-12. doi:10.1016/j.jnucmat.2009.10.060.

[76] P. Bossis, Comparison of the High Burn-Up Corrosion on M5 and Low Tin Zircaloy-4, in: 14th Int. Symp. Zircon. Nucl. Ind., 2005: pp. 494-525.

[77] L.F. Bossis P, Thomazet J, Study of the Mechanisms Controlling the Oxide Growth Under Irradiation: Characterization of Irradiated Zircaloy-4 and Zr-lNb-O Oxide Scales, Zircon. Nucl. Ind. - 13th Int. Symp. (n.d.).

[78] A. Shishov, V. N., Nikulina, A. V., Markelov, V. A., Peregud, M. M., Kozlov, A. V., et al. S.A., Influence of Neutron Irradiation and Dislocation Structure and Phase Composition of Zr-Base Alloys, Zircon. Nucl. Ind. Seventh Int. Symp. ASTM STP 939. (n.d.). 
[79] V.N. Shishov, M.M. Peregud, A. V Nikulina, P. V Shebaldov, A. V Tselischev, A.E. Novoselov, G.P. Kobylyansky, Z.E. Ostrovsky, V.K. Shamardin, Influence of zirconium alloy chemical composition on microstructure formation and irradiation induced growth, in: 13th Int. Symp. Onm Zr Nucl. Ind., ASTM International, 100 Barr Harbor Drive, PO Box C700, West Conshohocken, PA 19428-2959, 2002: pp. 758-778. doi:10.1520/STP11415S.

[80] V.N. Shishov, M.M. Peregud, A. V. Nikulina, V.F. Kon'Kov, V. V. Novikov, V.A. Markelov, T.N. Khokhunova, G.O. Kobylyansky, A.E. Novoselov, Z.E. Ostrovsky, A. V. Obukhov, Structure-phase state, corrosion and irradiation properties of $\mathrm{Zr}-\mathrm{Nb}-\mathrm{Fe}-\mathrm{Sn}$ system Alloys, J. ASTM Int. 5 (2008) 724-743. doi:10.1520/JAI101127.

[81] S. Doriot, D. Gilbon, J.-L. Bechade, M.-H. Mathon, L. Legras, J.-P. Mardon, Microstructural stability of M5 (TM) alloy irradiated up to high neutron fluences, in: Zircon. Nucl. Ind. 14th Int. Symp., ASTM International, 2005: pp. 175-201. doi:10.1520/STP37507S.

[82] V.N. Shishov, M.M. Peregud, A. V. Nikulina, V.F. Kon'kov, V. V. Novikov, V.A. Markelov, T.N. Khokhunova, G.P. Kobylyansky, A.E. Novoselov, Z.E. Ostrovsky, A. V. Obukhov, Structure-Phase State, Corrosion and Irradiation Properties of $\mathrm{Zr}-\mathrm{Nb}-\mathrm{Fe}-\mathrm{Sn}$ System Alloys, in: Zircon. Nucl. Ind. 15th Int. Symp., ASTM International, 100 Barr Harbor Drive, PO Box C700, West Conshohocken, PA 19428-2959, 2009: pp. 724-72420. doi:10.1520/STP48164S.

[83] R.S. Nelson, J.A. Hudson, D.J. Mazey, The stability of precipitates in an irradiation environment, J. Nucl. Mater. 44 (1972) 318-330. doi:10.1016/0022-3115(72)90043-8.

[84] K. Sakamoto, K. Une, M. Aomi, T. Otsuka, K. Hashizume, Change of chemical states of niobium in the oxide layer of zirconium-niobium alloys with oxide growth, J. Nucl. Sci. Technol. 52 (2015) 1259-1264. doi:10.1080/00223131.2015.1058196. 